\title{
穿心莲内酯抗肿瘤作用衍生物的合成研究进展
}

\author{
彭宇然 $a, b$ 孙亦诚 ${ }^{a}$ 王德才*, $a$ 韦 萍 $b$ \\ 欧阳平凯 ${ }^{b}$ 周国春 ${ }^{a}$ \\ ( ${ }^{a}$ 南京工业大学药学院 南京 211816) \\ ( $b$ 南京工业大学生物与制药工程学院 南京 211816)
}

\begin{abstract}
摘要 作为爵床科植物穿心莲的主要活性成分之一, 穿心莲内酯具有广泛的药理活性. 近年来, 已有大量研究表明对 穿心莲内酯进行结构改造可提升其抗肿瘤作用. 因此, 根据穿心莲内酯行生物结构特点, 将其按照基础骨架不同分为 五类, 分别为穿心莲内酯骨架衍生物、14-去氧穿心莲内酯骨架衍生物、脱水穿心莲内酯骨架衍生物、异穿心莲内酯骨 架衍生物以及 12-环替代的穿心莲内酯骨架衍生物. 在此基础上, 对穿心莲内酯衍生物的合成以及抗肿瘤活性结果进行 综述, 并初步总结其构效关系. 最后, 对衍生物未来的研究趋势进行了展望.
\end{abstract}

关键词 穿心莲内酯; 衍生物; 合成; 抗肿瘤

\section{Recent Progress in Synthesis of Andrographolide Derivatives with Anti-tumor Activities}

\author{
Peng, Yuran ${ }^{a, b} \quad$ Sun, Yicheng ${ }^{a} \quad$ Wang, Decai ${ }^{*, a} \quad$ Wei, Ping $^{b}$ \\ Ouyang, Pingkai $^{b} \quad$ Zhou, Guochun $^{a}$ \\ ( ${ }^{a}$ College of Pharmaceutical Sciences, Nangjing Tech University, Nanjing 211816) \\ ( ${ }^{b}$ College of Biotechnology and Pharmaceutical Engineering, Nanjing Tech University, Nanjing 211816)
}

\begin{abstract}
As one of the major active constituents in Andrographis panniculata (Burm. f.) Nees of Acanthaceae family, andrographolide is proved to possess a wide range of biological activities. In recent years, numerous studies show that the structural modification of andrographolide could enhance its anti-tumor activities. Therefore, according to the structural properties of andrographolide derivatives, five types of derivatives classified by different basic skeletons are denoted as the skeleton of andrographolide derivatives, the skeleton of 14-deoxyandrographolide derivatives, the skeleton of dehydroandrographolide derivatives, the skeleton of isoandrographolide derivatives and the skeleton of 12-ring replaced andrographolide derivatives. On this basis, the synthesis and anti-tumor activities of andrographolide derivatives are reviewed, and the structure activity relationship are also summarized preliminarily. The future trends of the derivatives research are discussed in the end.

Keywords andrographolide; derivatives; synthesis; anti-tumor
\end{abstract}

穿心莲内酯 ${ }^{[1]}$ 又名穿心莲乙素、雄茸内脂, 系爵床 科植物穿心莲的主要活性成分之一，属二萜内酯类天然 产物, 临床上主要应用于清热解毒、抗菌消炎, 特别是 针对上呼吸道感染疗效显著, 被誉为天然抗生素药物 ${ }^{[2]}$. 近年来, 穿心莲内酯的抗肿瘤活性逐渐成为研究重点, 现已发现其在诱导肿瘤细胞凋亡 ${ }^{[3]}$ 、抑制肿瘤细胞周 期 ${ }^{[4]}$ 以及抑制肿瘤血管生成 ${ }^{[5]}$ 等方面具有一定作用. 尽 管如此, 由于穿心莲内酯的低水溶性 ${ }^{[6]}$ 与相对较弱的稳
定性 ${ }^{[7]}$ 导致其抗肿瘤活性无法得到进一步的应用，所以 结构改造工作成为提高生物活性的主要研究方向.

穿心莲内酯的化学结构(图 1)以反式十氢萗环为母 核, 环外具有端头双键以及 $\alpha, \beta$-不饱和- $\gamma$-丁内酯结构. 宏观上，整个分子可以视为一个柔性结构母核通过 C-11 和 C-12 与一个刚性结构相连, 其中刚性结构环外 $\alpha, \beta$-不饱和- $\gamma$-丁内酯在 C-12,13 位双键的作用下使得 C-13、C-14、C-16 处于同一平面, 键角均约在 $120^{\circ}$, 导

\footnotetext{
* E-mail: dcwang@njtech.edu.cn

Received January 21, 2015; revised March 5, 2015; published online March 9, 2015.

Project supported by the National Natural Science Foundation of China (No. 30973621).

国家自然科学基金(No. 30973621)资助项目.
} 
致内酯环张力增大, 结构稳定性降低, 另外酯基还有易 开环水解的特性 ${ }^{[7]}$; 结构中含有三个羟基, 分别是 $\mathrm{C}-3$ 位仲羟基、C-14 位烯丙位仲羟基和 C-19 位伯羟基, 其 中以 C-14 位烯丙位仲羟基的化学性质最为活泼, 在羟 基氧化过程中会发生烯丙位的双键迁移 ${ }^{[8]}$, 或在碱性较 强的环境下会发生羟基消去甚至消去后双键迁移 ${ }^{[9]}$. 可 见, 穿心莲内酯多官能团的分子结构决定其化学性质较 为活泼, 在结构改造上有较大空间.

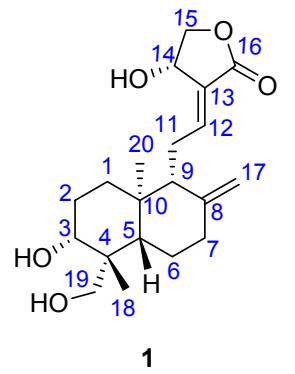

图 1 穿心莲内酯的化学结构及其碳原子编号

Figure 1 Chemical structure of andrographolide and the serial number of its carbon atom

2000 年后, 包括中国黄文龙课题组、印度 Nanduri 课题组在内的十余个相关工作团队, 对穿心莲内酯进行 结构改造并研究其抗肿瘤活性. 由于每个课题组在衍生 物结构设计上均有各自特点, 所以本文综合其结构特 性, 将衍生物分为五类基础结构骨架, 分别是穿心莲内 酯骨架衍生物 I、14-去氧穿心莲内酯骨架衍生物 II、脱 水穿心莲内酯骨架衍生物 III、异穿心莲内酯骨架衍生 物 IV 以及 12-环替代的穿心莲内酯骨架衍生物 V. 本文 将根据此五类基本骨架对穿心莲内酯抗肿瘤作用衍生 物的合成与活性进行综述, 并在此基础上进行构效关系 的初步总结.

\section{1 穿心莲内酯骨架衍生物}

以穿心莲内酯为基础骨架(图 2), 其改造范围包括: 三个羟基不同程度的醚化、酯化、构型翻转或氧化等; 端 头烯键的环氧化或还原; 共轭烯键的还原或 [3+2]环加 成.

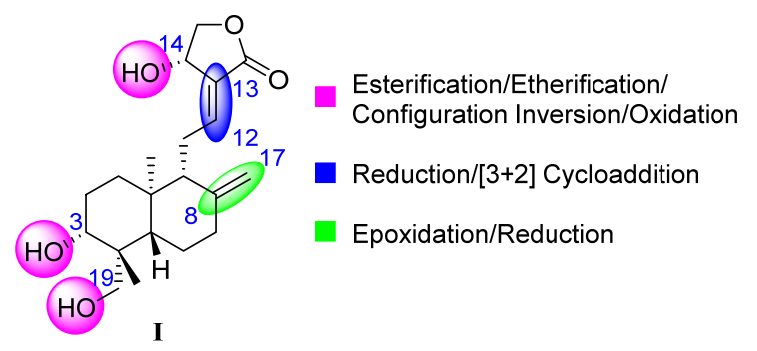

图 2 穿心莲内酯骨架的结构改造

Figure 2 Structural modification of andrographolide skeleton
最早对穿心莲内酯结构进行系统性改造并研究其 抗肿瘤作用的印度 Nanduri 课题组 ${ }^{[10]}$ 于 2001 年公开专 利将穿心莲内酯的三个羟基衍生化并重点在 C-14 位羟 基引入不同基团形成醚键或酯键，如 Scheme 1 所示. 课 题组考察了衍生物 3a 3f 对多项肿瘤细胞的抑制能力, 发现部分衍生物活性优于穿心莲内酯，其中衍生物 3a 对人乳腺癌细胞 MCF-7/ADR 的 $\mathrm{GI}_{50}$ 值达 $0.4 \mu \mathrm{mo} / \mathrm{L}$. 值 得一提的是, 实验所合成的衍生物 3,19-异亚丙基穿心 莲内酯 2a 在后续大量改造工作中成为了重要合成中间 体, 所以 Nanduri 课题组 ${ }^{[9]}$ 对结构改造工作的开创性冉 庸置疑. 2004 年, 该课题组进一步结合专利内容 ${ }^{[1]}$ 合成 系列环氧化衍生物 4 7 (Scheme 1) 并研究其抗肿瘤作 用, 实验将穿心莲内酯 C-8,17 位端头烯键环氧化, 并在 此基础之上对三个羟基进行酯化，提供了选择性引入乙 酰基的合成方法，考察三个羟基对乙酰基所展现出不同 的结合能力. 生物活性方面, 研究发现穿心莲内酯环氧 化物 4 对多项肿瘤细胞抑制能力与穿心莲内酯基本持 平，而进一步三羟基乙酰化产物 5a 活性明显增强，针对 肾癌细胞 $\mathrm{A} 498$ 的 $\mathrm{GI}_{50}$ 值达 $0.25 \mu \mathrm{mol} / \mathrm{L}$, 并且化合物 5h、5k、5l、5n 也有良好的体外抗肿瘤活性，其中 14肉桂酰基衍生物 $5 \mathbf{k}$ 在体内实验中展现出更好的抗肿瘤 活性. 由此, 课题组认为 C-8,17 位环氧化结构可增强穿 心莲内酯抗肿瘤作用. 实验进一步以化合物 $\mathbf{5 a}$ 为原料, 环氧开环得到 C-17 位醛基产物 6a 和分子内环合产物 6b, 其中化合物 $6 \mathbf{b}$ 虽为副产物收率不高, 但其并三环 结构骨架为衍生物结构设计又开创了一条重要思路，而 化合物 $6 \mathrm{a}$ 的醛基还原产物 7 则是在穿心莲内酯基础结 构上增加了一个羟基, 这一改造相较于化合物 6a 对抑 制肿瘤细胞活性有不同程度的提高. 另外, 实验 ${ }^{[9]}$ 利用 $\mathrm{NaBH}_{4} / \mathrm{MeOH}$ 体系选择性还原 C-12,13 位双键得到衍生 物 8 (Scheme 1), 尽管其活性普遍降低, 但针对前列腺 癌细胞 DU145 的 $\mathrm{GI}_{50}$ 值达 $2 \mu \mathrm{mol} / \mathrm{L} .2007$ 年, Jada 课题 组 ${ }^{[12]}$ 重点考察衍生物 $2 \mathrm{a}$ 与 $3 \mathrm{~h}$ 对 60 种肿瘤细胞系的抑 制能力, 发现其活性大多高于穿心莲内酯，化合物 $\mathbf{3 h}$ 对 肾透明细胞癌 CAKI-1 的 $\mathrm{GI}_{50}$ 值达 $0.39 \mu \mathrm{mol} / \mathrm{L}$, 但 $\mathrm{LC}_{50}$ 值亦达到 $10.71 \mu \mathrm{mol} / \mathrm{L}$, 证明活性增强的同时毒性也更 大.

2006 年, Jada 等 ${ }^{[13]}$ 延续衍生物 $\mathbf{2 b}$ 与 $\mathbf{2 c}$ 的结构骨架, 将穿心莲内酯 C-3,19 位羟基与芳醛偶联形成十氢荎环 并 C-2'位芳环取代的 1',3'-二氧六环结构衍生物 9a 9i、

10a 10u (Scheme 2), 并研究其对 MCF-7 与 HCT-116 肿瘤细胞抑制能力, 其中 4-硝基苯基衍生物 $\mathbf{1 0 h}$ 的 $\mathrm{GI}_{50}$ 值分别达到 0.7 和 $2.6 \mu \mathrm{mol} / \mathrm{L}$ 且 $\mathrm{LC}_{50}$ 值分别在 96.6 和 $95.1 \mu \mathrm{mol} / \mathrm{L}$ ，不仅抑制活性明显优于穿心莲内酯，而且 毒性更低. 实验进一步考察衍生物 9b 9c、9e 9f、9h、 


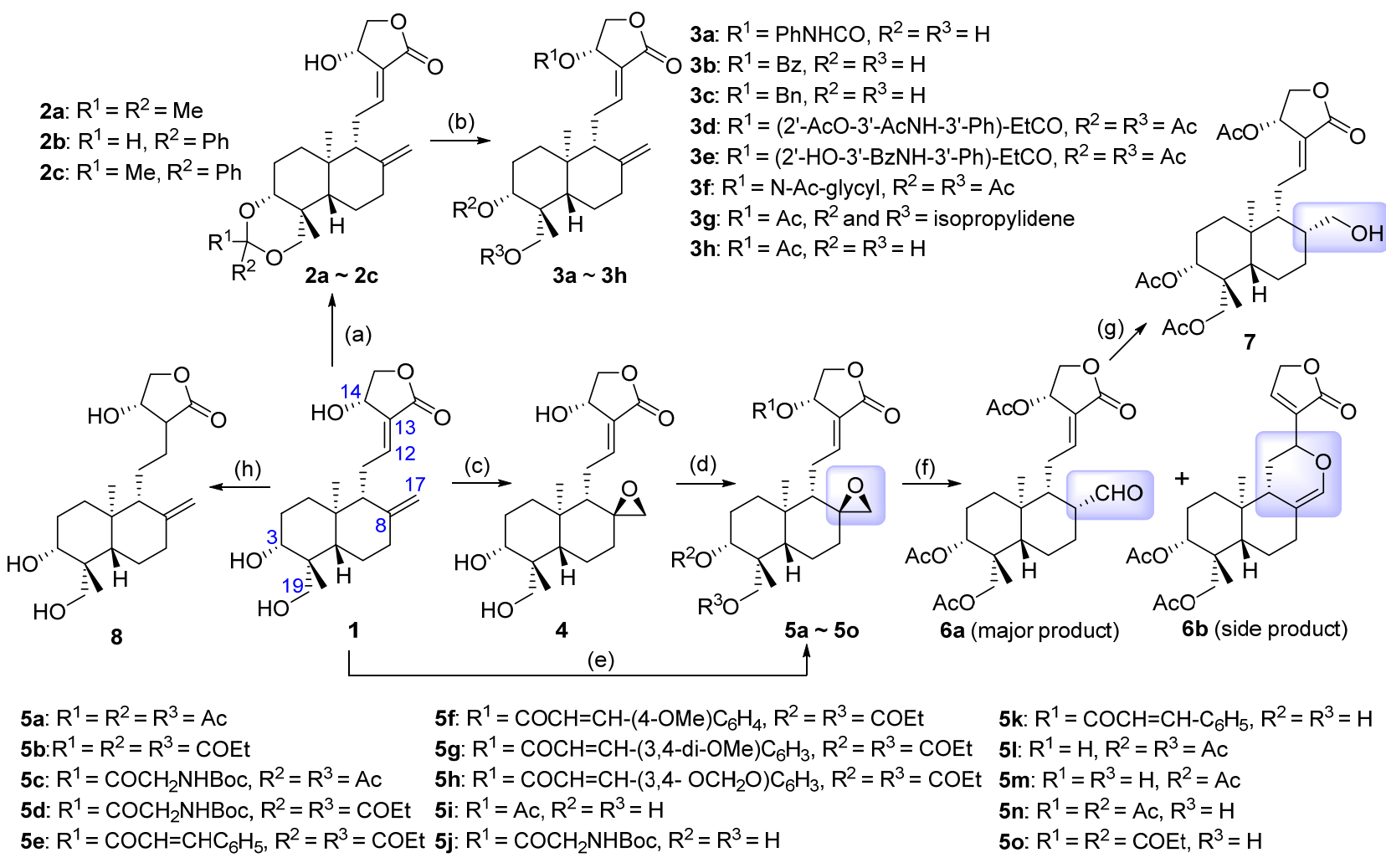

Reagents and conditions: (a) 2,2-dimethoxy propane, benzaldehyde or acetophenone, $\mathrm{C}_{6} \mathrm{H}_{6}$, DMSO, PPTS, reflux, $0.5 \mathrm{~h}$; (b) for $\mathbf{3 a} \sim \mathbf{3} \mathbf{c}$ i) phenyl isocyanate or $\mathrm{R}^{1} \mathrm{Cl}$, TEA, DCM, r.t., $0.5 \mathrm{~h}$, ii) $\mathrm{AcOH} / \mathrm{H}_{2} \mathrm{O}(\mathrm{V} / \mathrm{V}=7 / 3)$, r.t., $15 \mathrm{~min}$; for $\mathbf{3 d} \sim \mathbf{3 f}$ i) $\mathrm{R}^{1} \mathrm{OH}$, DCC, TEA, DCM, r.t., $1 \mathrm{~h}$, ii) AcOH/ $\mathrm{H}_{2} \mathrm{O}(\mathrm{VIV}=7 / 3)$, r.t., $15 \mathrm{~min}$, iii) $\mathrm{Ac}_{2} \mathrm{O}, \mathrm{ZnCl}_{2}, 80{ }^{\circ} \mathrm{C}, 5 \sim 30 \mathrm{~min}$; for $3 \mathrm{~g} \mathrm{Ac}_{2} \mathrm{O}, \mathrm{ZnCl}_{2}$, reflux, 45 min; for $3 \mathbf{h}$ i) $\mathrm{Ac}_{2} \mathrm{O}, \mathrm{ZnCl}_{2}$, reflux, 45 min, ii) $\mathrm{AcOH} / \mathrm{H}_{2} \mathrm{O}(\mathrm{V} / \mathrm{V}=7 / 3)$, r.t., $10 \mathrm{~min}$; (c) $\mathrm{m}$-CPBA, TCM, $\mathrm{MeOH}$, r.t., $6 \mathrm{~h}$; (d) for $\mathbf{5 a} \sim \mathbf{5 b}$ acetic or propionic anhydride, reflux, $30 \mathrm{~min}$ (required isomer); for $\mathbf{5 c} \sim \mathbf{5 h}$ i) 2,2-dimethoxy propane, $\mathrm{C}_{6} \mathrm{H}_{6}$, DMSO, PPTS, reflux, $8 \mathrm{~h}$ (required isomer), ii) $\mathrm{R}^{1} \mathrm{COOH}, \mathrm{CICOOEt}$, TEA, DCM, r.t., $1 \mathrm{~h}$, iii) $\mathrm{AcOH} / \mathrm{H}_{2} \mathrm{O}(\mathrm{V} / \mathrm{V}=7 / 3)$, r.t., $15 \mathrm{~min}$, iv) acetic or propionic anhydride, reflux, $30 \mathrm{~min}$; for $\mathbf{5 i} \sim \mathbf{5 k}$ i) 2,2-dimethoxy propane, $\mathrm{C}_{6} \mathrm{H}_{6}$, DMSO, PPTS, reflux, $8 \mathrm{~h}$ (required isomer), ii) acetic anhydride, reflux, $1 \mathrm{~h}$ or $\mathrm{R}^{1} \mathrm{COOH}, \mathrm{CICOOEt}$, TEA, DCM, r.t., $1 \mathrm{~h}$, iii) $\mathrm{AcOH} / \mathrm{H}_{2} \mathrm{O}(\mathrm{VIV}=7 / 3)$, r.t., $15 \mathrm{~min}$; (e) for $\mathbf{5 l}$ i) acetic acid, $70{ }^{\circ} \mathrm{C}, 6 \mathrm{~h}$, ii) $\mathrm{m}$-CPBA, DCM, r.t., $4 \mathrm{~h}$ (required isomer); for $\mathbf{5 m} \sim \mathbf{5 o}$ i) $\mathrm{TrCl}, \mathrm{Py}, 60{ }^{\circ} \mathrm{C}, 6 \mathrm{~h}$, ii) $m$-CPBA, DCM r.t., $2 \mathrm{~h}$ (required isomer), iii) acetic or propionic anhydride, reflux, $30 \mathrm{~min}$, iv) $\mathrm{HCOOH}$, $\mathrm{DCM}$, r.t., $30 \mathrm{~min}$; (f) $\mathrm{BF}_{3} / \mathrm{Et}_{2} \mathrm{O}, \mathrm{DCM}, 0{ }^{\circ} \mathrm{C}, 10 \mathrm{~min}$; (g) $\mathrm{NaBH}_{4}, \mathrm{MeOH}, 0{ }^{\circ} \mathrm{C}, 30 \mathrm{~s}$; (h) i) 2,2-dimethoxypropane, $\mathrm{C}_{6} \mathrm{H}_{6}$, DMSO, PPTS, reflux, 2 h, ii) $\mathrm{NaBH}_{4}, \mathrm{MeOH}$, r.t., $1 \mathrm{~h}$, iii) $\mathrm{AcOH} / \mathrm{H}_{2} \mathrm{O}(V / V=7 / 3)$, r.t., $15 \mathrm{~min}$

图式 1 穿心莲内酯衍生物 2 7 的合成

Scheme 1 Synthesis of andrographolide derivatives $2 \sim 7$

$10 \mathrm{a} \sim 10 \mathrm{~b}$ 与 10i 对九大类型肿瘤细胞的抑制活性, 结果 发现各项数据普遍优于穿心莲内酯. Hocker 等 ${ }^{[14]}$ 通过分 子对接与模拟技术以及蛋白质印迹法等生物实验发现 衍生物 9a、9d、9g 可抑制鸟苷酸交换因子从而达到中 止肿瘤生长的效果. 2010 年, Menon 与 Bhat ${ }^{[15]}$ 利用固体 酸催化剂 Amberlyst-15 合成穿心莲内酯衍生物 10a、

10g、11a 11c 与 12a 12c (Scheme 2), 其中衍生物 10a、 $10 \mathrm{~g} 、 11 \mathrm{a} \sim 11 \mathrm{c}$ 的结构与 Jada 课题组的一致, 而衍生物 $12 \mathrm{a} \sim 12 \mathrm{c}$ 则是选择性于 C-19 位着基引入甲酰基、对甲 苯磺酰基以及对甲苯磺酰胺甲酰基, 活性研究结果发现 化合物 10g、11a、11c 对肺癌细胞 A549 具有一定的抑 制作用.

Saeeng 等 ${ }^{[16]}$ 利用 TBS、TIPS、TBDPS 和 $T r$ 四种常 用羟基保护基选择性保护穿心莲内酯 C-19 位羟基得到 衍生物 12d 12h, 再将剩余羟基全部或选择性乙酰化 得到衍生物 13a 13m (Scheme 3). 结果发现羟基醚化
后的穿心莲内酯具有一定的细胞毒活性, 可抑制肿瘤细 胞增长, 其中化合物 12e、12g 与 13c 对 P-388、KB、 COL-2、MCF-7、LU-1 与 ASK 等六种肿瘤细胞抑制能 力明显, 且以 C-19 位三苯甲醚衍生物 $12 \mathrm{~g}$ 最优, 各项 $\mathrm{ED}_{50}$ 值均不高于天然产物玫瑰树碱. 文献总结构效关 系发现, 在 C-19 位羟基引入大结构基团可以提升穿心 莲内酯的抗肿瘤活性, 而继续在 C-3,14 位羟基上引入乙 酰基则无明显帮助.

除了将 C-19 位差基醚化与酯化外, 薛晓雯课题组 ${ }^{[17]}$ 于 2013 年, 首次设计合成穿心莲内酯 C-19 位羟基氧 化衍生物 14 18 (Scheme 4), 并研究其抗肿瘤活性. 该 课题组总结穿心莲提取物与抗肿瘤作用的构效关系, 认 为 C-14 位着基引入乙酰基或 C-19 位差基氧化成羧酸均 可增加化合物抗肿瘤活性，而 C-3 位羟基脱氢成酮则会 降低活性. 实验以此为设计思想, 先将穿心莲内酯 C-14 位羟基酯化，再利用 TEMPO 选择性氧化 C-19 位着基成 


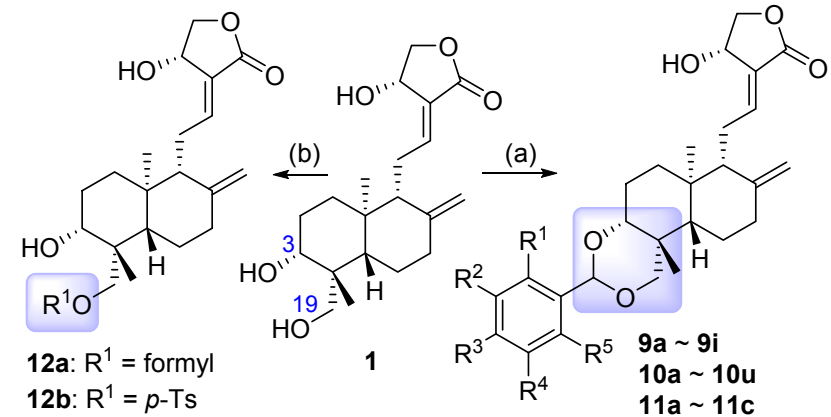

12c: $R^{1}=p$-methylphenylsulfonaminocarbonyl

9a: $R^{1}=H, R^{2}=C l, R^{3}=F, R^{4}=R^{5}=H$

9b: $R^{1}=F, R^{2}=R^{3}=R^{4}=R^{5}=H$

9c: $R^{1}=\mathrm{Cl}, \mathrm{R}^{2}=\mathrm{R}^{3}=\mathrm{R}^{4}=\mathrm{R}^{5}=\mathrm{H}$

9d: $R^{1}=B r, R^{2}=R^{3}=R^{4}=R^{5}=H$

9e: $R^{1}=H, R^{2}=F, R^{3}=R^{4}=R^{5}=H$

9f: $\mathrm{R}^{1}=\mathrm{H}, \mathrm{R}^{2}=\mathrm{Cl}, \mathrm{R}^{3}=\mathrm{R}^{4}=\mathrm{R}^{5}=\mathrm{H}$

9g: $R^{1}=H, R^{2}=B r, R^{3}=R^{4}=R^{5}=H$

9h: $R^{1}=R^{2}=H, R^{3}=F, R^{4}=R^{5}=H$

9i: $R^{1}=R^{2}=H, R^{3}=B r, R^{4}=R^{5}=H$

10a: $R^{1}=R^{2}=H, R^{3}=C l, R^{4}=R^{5}=H$

10b: $R^{1}=\mathrm{Cl}, \mathrm{R}^{2}=\mathrm{H}, \mathrm{R}^{3}=\mathrm{F}, \mathrm{R}^{4}=\mathrm{R}^{5}=\mathrm{H}$

10c: $R^{1}=M e, R^{2}=R^{3}=R^{4}=R^{5}=H$

10d: $R^{1}=H, R^{2}=M e, R^{3}=R^{4}=R^{5}=H$

10e: $R^{1}=R^{2}=H, R^{3}=M e, R^{4}=R^{5}=H$

10f: $R^{1}=N_{2}, R^{2}=R^{3}=R^{4}=R^{5}=H$

10g: $R^{1}=H, R^{2}=N_{2}, R^{3}=R^{4}=R^{5}=H$

10h: $R^{1}=R^{2}=H, R^{3}=N_{2}, R^{4}=R^{5}=H$

10i: $R^{1}=\mathrm{Cl}, \mathrm{R}^{2}=\mathrm{R}^{3}=\mathrm{H}, \mathrm{R}^{4}=\mathrm{NO}_{2}, \mathrm{R}^{5}=\mathrm{H}$

10j: $R^{1}=\mathrm{OH}, \mathrm{R}^{2}=\mathrm{R}^{3}=\mathrm{H}, \mathrm{R}^{4}=\mathrm{NO}_{2}, \mathrm{R}^{5}=\mathrm{H}$

10k: $R^{1}=H, R^{2}=R^{3}=$ OMe, $R^{4}=R^{5}=H$

10I: $R^{1}=H, R^{2}=O M e, R^{3}=H, R^{4}=O M e, R^{5}=H$

10m: $\mathrm{R}^{1}=\mathrm{OMe}, \mathrm{R}^{2}=\mathrm{H}, \mathrm{R}^{3}=\mathrm{OMe}, \mathrm{R}^{4}=\mathrm{R}^{5}=\mathrm{H}$

10n $R^{1}=H, R^{2}=F, R^{3}=O M e, R^{4}=R^{5}=H$

10o: $R^{1}=H, R^{2}=C l, R^{3}=O M e, R^{4}=R^{5}=H$

10p: $R^{1}=H, R^{2}=B r, R^{3}=O M e, R^{4}=R^{5}=H$

10q: $R^{1}=H, R^{2}=M e, R^{3}=O M e, R^{4}=R^{5}=H$

10r: $R^{1}=O H, R^{2}=O M e, R^{3}=R^{4}=R^{5}=H$

10s: $R^{1}=H, R^{2}=O H, R^{3}=O M e, R^{4}=R^{5}=H$

10t: $R^{1}=H, R^{2}=R^{3}=O H, R^{4}=R^{5}=H$

10u: $R^{1}=$ OEt, $R^{2}=H, R^{3}=O H, R^{4}=R^{5}=H$

11a: $R^{1}=R^{2}=H, R^{3}=O M e, R^{4}=R^{5}=H$

11b: $R^{1}=F, R^{2}=O M e, R^{3}=O H, R^{4}=R^{5}=H$

11c: $R^{1}=H, R^{2}=R^{3}=O \mathrm{CH}_{2} \mathrm{O}, \mathrm{R}^{4}=\mathrm{R}^{5}=\mathrm{H}$

Reagents and conditions: (a) for $\mathbf{9 a} \sim \mathbf{9 i} \mathrm{PhCHO}, \mathrm{ZnCl}_{2}$, DMSO, r.t. $5 \sim 6 \mathrm{~h}$; for 10a $\sim 10 \mathrm{u}$ PhCHO, PPTS, DMSO, $70{ }^{\circ} \mathrm{C}, 2 \sim 3 \mathrm{~h}$; for 11a 11c PhCHO, Amberlyst-15, 1,4-dioxane, reflux, $5 \mathrm{~h}$. (b) for 12a formic acid, Amberlyst-15, reflux, $4 \mathrm{~h}$; for 12b PTSC, Py, THF, $28{ }^{\circ} \mathrm{C}, 24 \mathrm{~h}$; for $12 \mathrm{c}$ Tosyl isocyanate, NaH, THF, $0{ }^{\circ} \mathrm{C}, 2 \mathrm{~h}$

图式 2 穿心莲内酯衍生物 9 12 的合成

Scheme 2 Synthesis of andrographolide derivatives $\mathbf{9} \sim \mathbf{1 2}$

醛得到衍生物 $14 \mathrm{a} \sim 14 \mathrm{~d}$, 接着一方面采用次氯酸盐氧 化醛成酸得到衍生物 $15 \mathrm{a} \sim 15 \mathrm{c}$; 另一方面先于 C-3 位引 入 $A c$ 基得到衍生物 16a 16d, 再氧化醛至酸 $17 \mathrm{a} \sim 17 \mathrm{~d}$, 并在羧基上引入不同基团成酯，得到衍生物 $18 \mathrm{a} \sim \mathbf{1 8 f}$, 亦或在羧基上引入不同基团成酰胺后脱去 C-14 位 TBS 基团得到衍生物 $\mathbf{1 8 g} \sim \mathbf{1 8 k}$, 最后将 C-14 位差基成酯得 到衍生物 18I 18u. 生物活性方面, C-19 位酯基衍生物

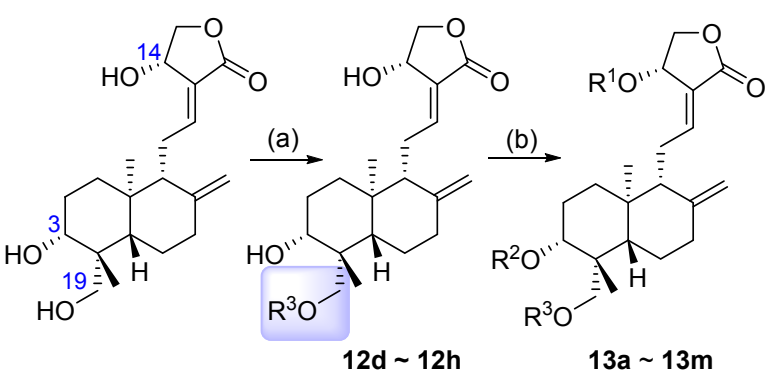

12d: $R^{1}=R^{2}=H, R^{3}=$ TBS 13e: $R^{1}=H, R^{2}=$ Ac, $R^{3}=$ TBDPS

12e: $R^{1}=R^{2}=H, R^{3}=$ TIPS $\quad$ 13f: $R^{1}=A c, R^{2}=H, R^{3}=$ TBDPS

12f: $R^{1}=R^{2}=H, R^{3}=$ TBDPS 13g: $R^{1}=R^{2}=A c, R^{3}=$ TBDPS

12g: $R^{1}=R^{2}=H, R^{3}=T r$

12h: $R^{1}=R^{2}=H, R^{3}=A c$

13a: $R^{1}=H, R^{2}=A c, R^{3}=T B S$

13h: $R^{1}=R^{2}=A c, R^{3}=T r$

13i: $R^{1}=A c, R^{2}=H, R^{3}=A c$

13b: $R^{1}=A c, R^{2}=H, R^{3}=$ TBS

13c: $R^{1}=R^{2}=$ Ac, $R^{3}=$ TBS

13d: $R^{1}=R^{2}=A c, R^{3}=$ TIPS

13j: $R^{1}=R^{2}=R^{3}=A C$

13k: $R^{1}=H, R^{2}=R^{3}=A c$

13I: $R^{1}=H, R^{2}=A c, R^{3}=H$

$13 \mathrm{~m}: R^{1}=R^{2}=A c, R^{3}=H$

Reagents and conditions: (a) for $\mathbf{1 2 d} \sim \mathbf{1 2 g}$ TBSCI, TIPSCI, TBDPSCl or TrCl, Py, r.t. $\sim 70{ }^{\circ} \mathrm{C}, 1 \sim 4 \mathrm{~h}$; for $12 \mathrm{~h} \mathrm{Ac} \mathrm{C}_{2} \mathrm{O}, 80{ }^{\circ} \mathrm{C}, 1 \mathrm{~h}$; (b) for 13a $\sim 13 \mathbf{k ~ A c} 2 \mathrm{O}, 70 \sim 145{ }^{\circ} \mathrm{C}, 1 \sim 18 \mathrm{~h}$; for 13I $\sim 13 \mathrm{~m} \mathrm{i)} \mathrm{Ac}_{2} \mathrm{O}$, $70 \sim 145{ }^{\circ} \mathrm{C}, 1 \sim 18 \mathrm{~h}$, ii) $\mathrm{HCOOH} / \mathrm{H}_{2} \mathrm{O}(V / V=9 / 1)$, THF, $0{ }^{\circ} \mathrm{C}, 0.5 \mathrm{~h}$

图式 3 穿心莲内酯衍生物 12 13 的合成

Scheme 3 Synthesis of andrographolide derivatives $\mathbf{1 2} \sim \mathbf{1 3}$

18a 18f 抑制结肠癌细胞 HCT-116 和乳腺癌细胞 MCF-7 的增殖能力不仅均强于穿心莲内酯, 部分甚至 优于传统抗癌药庚铂. 其中, 酯基衍生物以化合物 $\mathbf{1 8 d}$ 最优, 在结肠癌细胞 HCT-116 上的 $\mathrm{IC}_{50}$ 值达到 1.18 $\mu \mathrm{mol} / \mathrm{L}$; 而酰胺基衍生物以化合物 $18 p$ 最优, 对 HCT-116 的 $\mathrm{IC}_{50}$ 值达到 $0.92 \mu \mathrm{mol} / \mathrm{L}$, 而对 MCF-7 乳腺 癌细胞的 $\mathrm{IC}_{50}$ 值亦达到 $0.65 \mu \mathrm{mol} / \mathrm{L}$, 另外化合物 $18 \mathrm{n}$ 在 前列腺癌细胞 DU145 上的 $\mathrm{IC}_{50}$ 值达到 $1.94 \mu \mathrm{mol} / \mathrm{L}$, 同 样具有深入研究的价值.

2010 年, Chowdhury 等 ${ }^{[18]}$ 在穿心莲内酯 $\mathbf{1}$ 和共轭烯 键还原穿心莲内酯 19 的 C-14 位羟基引入琥珀酸酐、戊 二酸酐、邻苯二酸酐或马来酸酐, 形成酯基得到系列衍 生物 20 27 (Scheme 5). 实验旨在药物以前药的形式进 入白血病肿瘤细胞内后发生酯基断裂，以达到抑制效 果. 结果发现衍生物 24a 和 25b 对三种白血病肿瘤细胞 U937、THP1、K562 的抑制活性均优于穿心莲内酯，但 与此同时，对两种正常细胞 L132、NIH3T3 的毒性也更 加明显, 而将共轭烯键还原后的衍生物 $22 \mathrm{a} \sim 22 \mathrm{~b}$ 、

$23 a \sim 23 b 、 26 a \sim 26 b$ 和 $27 a \sim 27 b$ 均未发现抑制活性，所 以文献认为环外 $\alpha, \beta$-不饱和- $\gamma$-丁内酯是穿心莲内酯衍生 物在抗肿瘤方面的必要结构. 实验深入考察化合物 24a 诱导 U937 肿瘤细胞调亡的能力, 结果显示为空白组的 十倍, 并且可观察到给药后的细胞形态变化. 结合上述 研究内容, 该课题组 ${ }^{[19]}$ 于 2014 年再次报道穿心莲内酯 C-14 位着基酯化系列衍生物 28 33 (Scheme 5)及其抗 


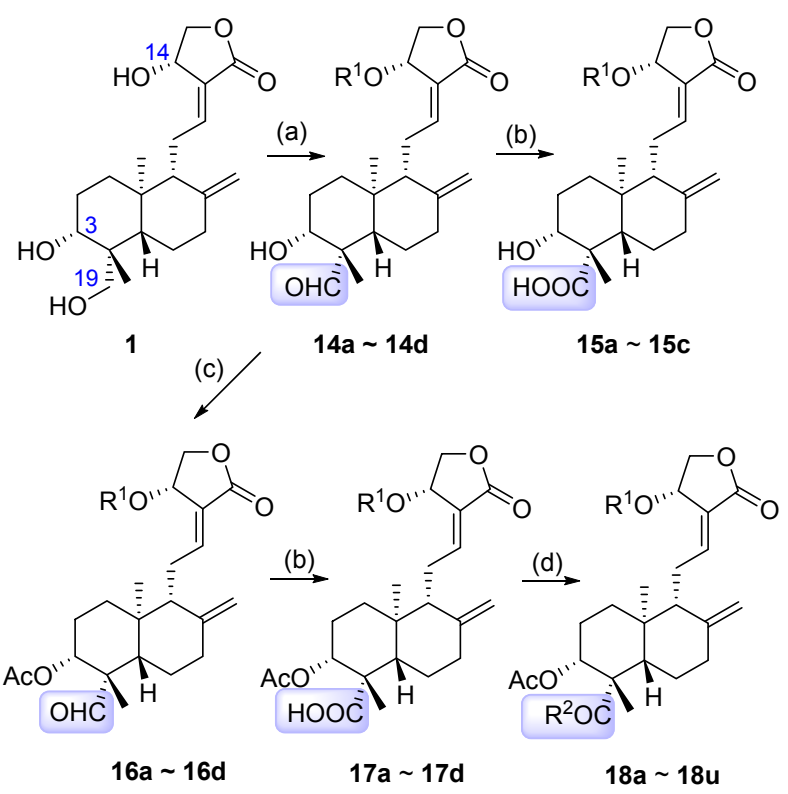

14a, 15a, 16a,17a: $R^{1}=A c \quad 14 c, 15 c, 16 c, 17 c: R^{1}=p-M c$ 14b, 15b, 16b, 17b: $R^{1}=B z \quad 14 d, \quad 16 d, 17 d: R^{1}=$ TBS

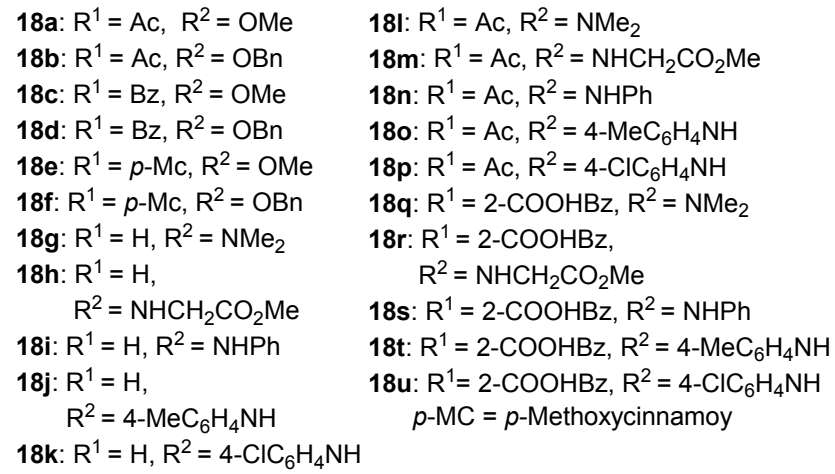

18k: $\mathrm{R}^{1}=\mathrm{H}, \mathrm{R}^{2}=4-\mathrm{ClC}_{6} \mathrm{H}_{4} \mathrm{NH}$

Reagents and conditions: (a) i) 2,2-dimethoxypropane, $p$ - $\mathrm{TsOH}$ (cat.), $\mathrm{C}_{6} \mathrm{H}_{6}, \mathrm{DMSO}, 80{ }^{\circ} \mathrm{C}, 1.5 \mathrm{~h}$, ii) for $14 \mathrm{a} \mathrm{Ac}_{2} \mathrm{O}$, reflux, $1.5 \mathrm{~h}$; for 14b BzCl, TEA, DMAP, DCM, r.t., 4 h; for 14c $p$-methoxycinnamic acid, $\mathrm{Tf}_{2} \mathrm{O}, \mathrm{TEA}, \mathrm{DCM}, 0{ }^{\circ} \mathrm{C}$ to r.t.; for $14 \mathrm{~d}$ TBSCl, imidazole, DMF, r.t., $10 \mathrm{~h}$; iii) $\mathrm{AcOH} / \mathrm{H}_{2} \mathrm{O}(V / V=7 / 3)$, r.t.; iv) TEMPO, TBAI, NCS, $\mathrm{DCM}, \mathrm{K}_{2} \mathrm{CO}_{3}-\mathrm{KHCO}_{3}$ buffer, $0{ }^{\circ} \mathrm{C}, 9 \mathrm{~h}$; (b) $\mathrm{NaClO}_{2}-\mathrm{NaH}_{2} \mathrm{PO}_{4}$, isopantene, $t-\mathrm{BuOH}$, DMSO, $0{ }^{\circ} \mathrm{C}$ to r.t., $48 \mathrm{~h}$; (c) $\mathrm{Ac}_{2} \mathrm{O}$, reflux, $1.5 \mathrm{~h}$; (d) for 18a, 18c, 18e Mel, $\mathrm{K}_{2} \mathrm{CO}_{3}$, DMF, r.t., $1 \mathrm{~h}$; for $18 \mathrm{~b}, 18 \mathrm{~d}, 18 \mathrm{f}$ $\mathrm{BnBr}, \mathrm{K}_{2} \mathrm{CO}_{3}$, DMF, r.t., $1 \mathrm{~h}$; for $\mathbf{1 8 g} \sim \mathbf{1 8 k}$ i) $(\mathrm{COCl})_{2}$, Amine, DCM, r.t., $5 \mathrm{~h}$, ii) TBAF, THF, $0{ }^{\circ} \mathrm{C}, 20 \mathrm{~min}$; for $18 \mathrm{I} \sim 18 \mathrm{u}$ i) $(\mathrm{COCl})_{2}$, Amine, DCM, r.t., $5 \mathrm{~h}$, ii) TBAF, THF, $0{ }^{\circ} \mathrm{C}, 20 \mathrm{~min}$, iii) $\mathrm{R}_{2}^{1} \mathrm{O}$, TEA, DCM, r.t. $\sim 135{ }^{\circ} \mathrm{C}, 0.5 \sim 6 \mathrm{~h}$

图式 4 穿心莲内酯衍生物 14 18 的合成

Scheme 4 Synthesis of andrographolide derivatives $\mathbf{1 4} \sim \mathbf{1 8}$

肿瘤活性结果. 实验在不改变共轭双键的前提下, 于 C-14 位羟基引入单卤代乙酰基并将端头烯键环氧化, 并首次同时得到两种环氧构型产物. 抗肿瘤活性方面, 文献通过 MTT 实验、免疫染色实验、FACS 实验、蛋白 免疫印迹实验以及 NF- $\mathrm{KB}$ 转录活性抑制实验综合发现 化合物 31b、31c 和 33c 对 HEK-293 和 MCF-7 肿瘤细胞 有明显优于初始原料的抑制作用, 并且对正常细胞 VERO 和 MCF-10A 的毒性较低, 其中以碘代乙酰化衍
生物 31c 效果最佳. 文章推测化合物 31c 抗肿瘤作用机 制是药物激活肿瘤抑制蛋白 $\mathrm{p} 53$, 使其下调 NF- $\mathrm{kB}$ 活性 同时上调 Bax/Bcl-xL 比率, 达到肿瘤细胞调亡效果. 另 外, 实验对比环氧化前后的衍生物活性变化, 认为端头 烯键环氧化对活性变化无明显影响，而活性差异主要在 于环氧构象的不同.

有研究 ${ }^{[20]}$ 表明, FXR(类法尼酯衍生物 X 受体)的过 度表达对肿瘤细胞具有促进作用，为寻找一种合适的 FXR 怙抗剂, 周国春课题组 ${ }^{[21]}$ 于 2014 年合成 14-芳基醚 系列衍生物 34 41 (Scheme 6), 并发现部分化合物对 FXR 具有一定的拮抗作用. 实验以衍生物 $2 \mathrm{a}$ 和 37 为合 成中间体, 通过 Mitsunobu 反应在 C-14 位引入构型翻转 的芳基醚衍生物 38a $\sim 38 \mathrm{i}$ 和 $40 \mathrm{a} \sim 40 \mathrm{~b}$ ，再脱除丙酮叉 得到对应的化合物 39a 39i 和 $41 a \sim 41 b$. 该结构改造 工作的创新点是衍生物 2a 通过 Mitsunobu 反应得到 C-14 位构型翻转的乙酰化产物 $\mathbf{3 4}$, 接着脱丙酮叉得到 衍生物 35, 再进一步脱 Ac 基得到关键中间体 36. 实验 首次通过化学手段得到穿心莲内酯 14-位差向异构体 36, 反应条件温和且收率稳定. 生物活性研究结果发现 衍生物 38g、39b 以及 39f 对 FXR 具有良好的拮抗活性. 实验总结其构效关系后发现 14( $(\beta)$ 构型系列衍生物中, 当苯环邻位是甲氧基取代或对位是硝基取代亦或同时 取代时，拮抗能力明显增强，并且 3,19-位丙酮叉的引入 也是活性变化的关键因素; 而相同取代基的 14( $\alpha$ )构型 衍生物则是活性降低、毒性增强.

针对穿心莲内酯 C-12,13 位双键的加成, 除了上述 Nanduri 课题组和 Chowdhury 课题组所作的加氢还原外, Mondal 等 ${ }^{[22]}$ 利用静红衍生物 $\mathbf{4 2 a} \sim \mathbf{4 2 n}$ 或二氧化范 $42 \mathrm{o}$ (底物 $\mathrm{I}$ ) 和肌氨酸 $43 \mathrm{a} 、 N$-苄基甘氨酸 $43 \mathrm{~b}$ 或脯氨酸 43c(底物 II) 与穿心莲内酯的 C- 12,13 位双键发生 [3+2] 环加成反应得到一系列具有多环的特殊立体构型的穿 心莲内酯衍生物 44 46 (Scheme 7). 其中 $N$-芐基甘氨 酸系列衍生物 $45 \mathrm{a} \sim 451$ 在多项抑制肿瘤细胞数据上基 本优于穿心莲内酯, 以衍生物 $\mathbf{4 5 h}$ 与 451 表现更优, 有 进一步的研究价值. 该课题组在保留内酯环的前提下合 成得到一系列空间结构复杂的化合物，而且在生物活性 上印证了其合成价值，这不仅是丰富了穿心莲内酯衍生 物的结构骨架, 更为后续的结构改造提供了更为大胆的 设计空间.

\section{14-去氧穿心莲内酯骨架衍生物}

以 14-去氧穿心莲内酯为基础骨架(图 3), 其改造范 围包括: 双羟基进行不同程度的醚化、酯化等; C-12 不 同基团的取代等; 端头烯键的环氧化、还原等.

2001 年, Nanduri 课题组 ${ }^{[23]}$ 公开专利提及以 14 -乙酰 
28a, 29a, 30a: $X=C l, R^{1}$ and $R^{2}=$ isopropylidene 28b, 29b, 30b: $X=B r, R^{1}$ and $R^{2}=$ isopropylidene 28c, 29c, 30c: $X=I, R^{1}$ and $R^{2}=$ isopropylidene 31a, 32a, 33a: $X=C l, R^{1}=R^{2}=H$ 31b, 32b, 33b: $X=B r, R^{1}=R^{2}=H$ 31c, 32c, 33c: $X=I, R^{1}=R^{2}=H$ (e)<smiles>[X]CC(=O)O[C@@H]1COC(=O)/C1=C/C</smiles>
$\mathrm{R}^{1}$<smiles>[R20]CC1CCCCC12CCCCC2</smiles>
$\mathrm{R}^{2} \mathrm{O}^{-1}-28 \mathrm{a}$ (d) $\left[\begin{array}{r}28 a \sim 28 b \underset{(f)}{(f)} \\ \rightarrow 28 c \\ -31 a \sim 31 c\end{array}\right.$ $\stackrel{(g)}{\longrightarrow}$<smiles>[X]CC(=O)O[C@H]1COC(=O)/C1=C/CC</smiles>

$\mathrm{R}^{1} \mathrm{O}^{\prime \prime}$ $\mathrm{R}^{2} \mathrm{O}^{-}$

$-29 a \sim 29 c$

(d)

$\rightarrow 32 \mathrm{a} \sim 32 \mathrm{c}$

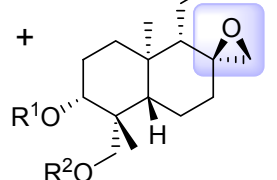

(d)

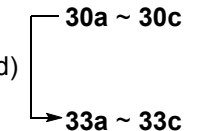

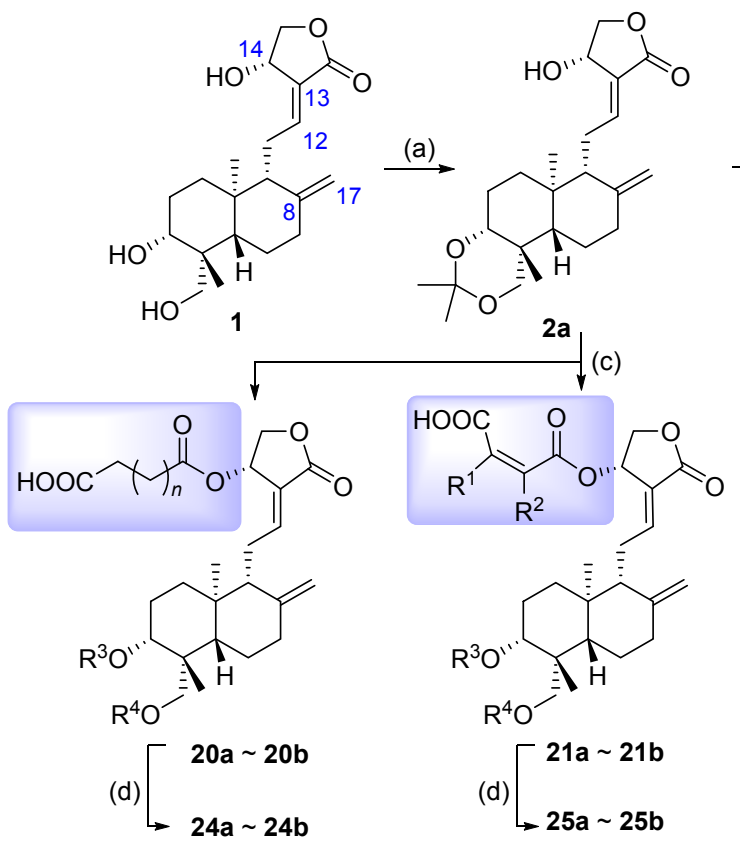<smiles>C=C1CC[C@@]2(C)[C@@H]3OC(C)(C)O[C@H]3CC[C@@H]2[C@@H]1CCC1C(=O)OC[C@H]1O</smiles>

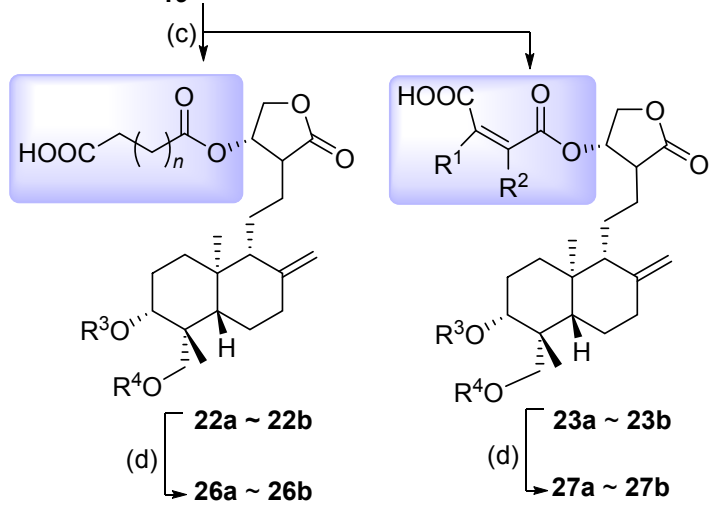

20a, 22a: $n=1, \mathrm{R}^{3}$ and $\mathrm{R}^{4}=$ isopropylidene 20b, 22b: $n=2, \mathrm{R}^{3}$ and $\mathrm{R}^{4}=$ isopropylidene 21a, 23a: $R^{1}=R^{2}=H, R^{3}$ and $R^{4}=$ isopropylidene

21b, 23b: $R^{1}$ and $R^{2}=C H=C H C H=C H, R^{3}$ and $R^{4}=$ isopropylidene

24a, 26a: $n=1, \mathrm{R}^{3}=\mathrm{R}^{4}=\mathrm{H}$

24b, 26b: $n=2, \mathrm{R}^{3}=\mathrm{R}^{4}=\mathrm{H}$

25a, 27a: $R^{1}=R^{2}=R^{3}=R^{4}=H$

25b, 27b: $\mathrm{R}^{1}$ and $\mathrm{R}^{2}=\mathrm{CH}=\mathrm{CHCH}=\mathrm{CH}, \mathrm{R}^{3}=\mathrm{R}^{4}=\mathrm{H}$

Reagents and conditions: (a) 2,2-dimethoxypropane, $p$ - $\mathrm{TsOH}$ (cat.), acetone, reflux, $2 \mathrm{~h}$; (b) $\mathrm{NaBH}_{4}, \mathrm{MeOH}, 0{ }^{\circ} \mathrm{C} \sim \mathrm{r.t.}, 1 \mathrm{~h}$; (c) succinic or glutaric or maleic or phthalic anhydride, DMAP (cat.), DCM, r.t., $4 \sim 6$ h; (d) $\mathrm{AcOH} / \mathrm{H}_{2} \mathrm{O}\left(V / V=7 / 3\right.$ ), r.t., $0.5 \mathrm{~h}$; (e) $\mathrm{XCH} \mathrm{COCl}_{2} \mathrm{Py}, \mathrm{DMAP}$ (cat.), THF, $0{ }^{\circ} \mathrm{C}, 0.5 \mathrm{~h}$; (f) $\mathrm{Nal}$, acetone, r.t., $3 \mathrm{~h}$; (g) $\mathrm{m}$-CPBA, DCM, $0{ }^{\circ} \mathrm{C}, 3 \mathrm{~h}$

图式 5 穿心莲内酯衍生物 19 33 的合成

Scheme 5 Synthesis of andrographolide derivatives $19 \sim 33$

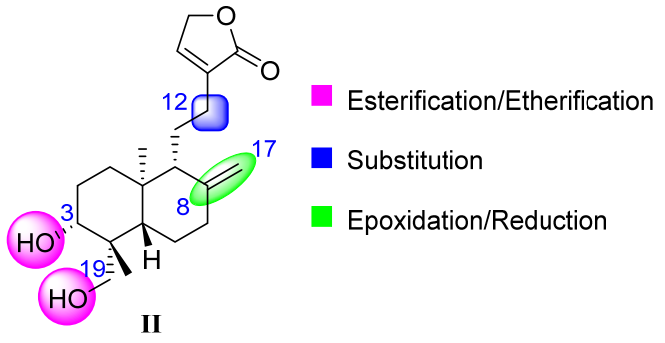

图 3 14-去氧穿心莲内酯骨架的结构改造

Figure 3 Structural modification of 14-deoxyandrographolide skeleton

氧基穿心莲内酯衍生物 $3 \mathrm{~g} \sim 3 \mathrm{~h} 、 13 \mathrm{p}$ 和 $47 \mathrm{a} \sim 47 \mathrm{~b}$ 为中 间体与芳胺类化合物合成得到 C-12 位取代的 14-去氧穿
心莲内酯衍生物(Scheme 8), 并考察衍生物 $\mathbf{4 8 a} \sim \mathbf{4 8 i}$ 的 抗肿瘤细胞活性. 结果发现衍生物 $48 \mathrm{~b}$ 对肺癌细胞 $\mathrm{H} 522$ 和卵巢癌细胞 SKOV3 的 $\mathrm{GI}_{50}$ 值达到 0.18 和 0.15 $\mu \mathrm{mol} / \mathrm{L}$; 衍生物 48c 对胶质瘤细胞 U251 的 $\mathrm{GI}_{50}$ 值达到 $0.07 \mu \mathrm{mol} / \mathrm{L}$. 随后, 该课题组首次通过化学手段合成天 然产物 14-去氧穿心莲内酯(穿心莲甲素)49 (Scheme 8), 该化合物与穿心莲内酯同属穿心莲总内酯但含量相对 较低，而文献所提供的羟基酯化、双键还原、酯基消除 三步反应收率较高且操作简便. 尽管化合物 49 对大多 肿瘤细胞抑制能力较低, 但对卵巢癌细胞 SKOV3 的 $\mathrm{GI}_{50}$ 值达到 $0.18 \mu \mathrm{mol} / \mathrm{L}$, 活性远远强于穿心莲内酯, 这 在选择性抑制肿瘤细胞方面具有长远意义. 
<smiles>C=C1CC[C@H]2[C@H](CO)[C@@H](O)CC[C@]2(C)[C@H]1C/C=C1\C(=O)OC[C@@H]1O</smiles>

1 $\stackrel{(a)}{\longrightarrow}$<smiles>CCCCCCOC1CC1</smiles>

(b)

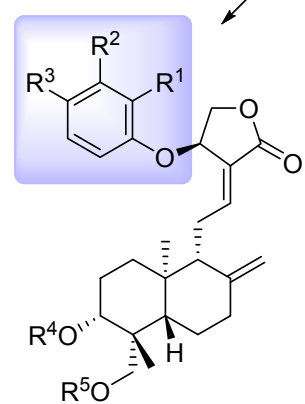

(c) $\longrightarrow \begin{array}{r}38 a \sim 38 i \\ -39 a \sim 39 i\end{array}$<smiles>C=C1CC[C@@]2(C)[C@H]3COC(C)(C)O[C@H]3CC[C@@H]2[C@H]1CCC</smiles>

$2 a$

34<smiles>C=C1CC[C@H]2[C@H](CO)[C@@H](O)CC[C@@]2(C)[C@H]1CCC</smiles>

35

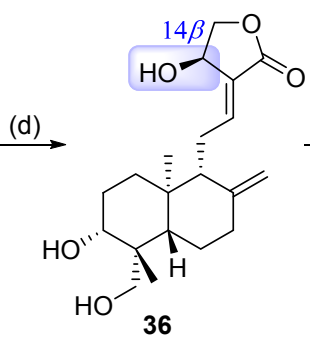

36

(a)

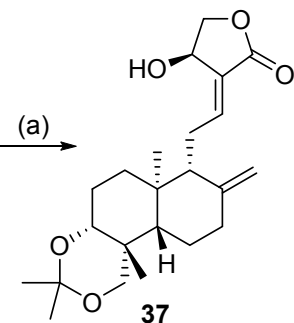

$\downarrow$ (b)

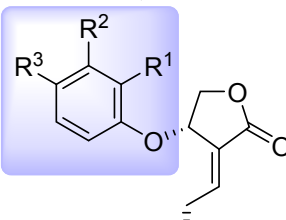

38g: $R^{1}=O M e, R^{2}=H, R^{3}=N O_{2}, R^{4}$ and $R^{5}=$ isopropylidene

38h: $R^{1}=M e, R^{2}=H, R^{3}=N_{2}, R^{4}$ and $R^{5}=$ isopropylidene;

38i: $R^{1}=F, R^{2}=H, R^{3}=N_{2}, R^{4}$ and $R^{5}=$ isopropylidene;

39a: $R^{1}=R^{2}=R^{3}=R^{4}=R^{5}=H ; 39 b: R^{1}=R^{2}=H, R^{3}=N_{2}, R^{4}=R^{5}=H$

39c: $R^{1}=H, R^{2}=N_{2}, R^{3}=R^{4}=R^{5}=H ; 39 d: R^{1}=N_{2}, R^{2}=R^{3}=R^{4}=R^{5}=H$;

39e: $R^{1}=\mathrm{CO}_{2}$ Et, $R^{2}=R^{3}=R^{4}=R^{5}=H$; 39f: $R^{1}=$ OMe, $R^{2}=R^{3}=R^{4}=R^{5}=H$;

39g: $R^{1}=O M e, R^{2}=H, R^{3}=N_{2}, R^{4}=R^{5}=H ; 39 h: R^{1}=M e, R^{2}=H, R^{3}=N_{2}, R^{4}=R^{5}=H$;

39i: $R^{1}=F, R^{2}=H, R^{3}=N_{2}, R^{4}=R^{5}=H$

40a: $R^{1}=R^{2}=H, R^{3}=N_{2}, R^{4}$ and $R^{5}=$ isopropylidene; 40b: $R^{1}=O M e, R^{2}=H, R^{3}=N_{2}, R^{4}$ and $R^{5}=$ isopropylidene; 41a: $R^{1}=R^{2}=H, R^{3}=N_{2}, R^{4}=R^{5}=H ; 41 b: R^{1}=O M e, R^{2}=H, R^{3}=N_{2}, R^{4}=R^{5}=H$

Reagents and conditions: (a) 2,2-dimethoxypropane, PPTS (cat.), DCM, $40{ }^{\circ} \mathrm{C}, 2 \mathrm{~h}$; (b) for $34 \mathrm{AcOH}, \mathrm{PPh}$, DIAD, THF, $0{ }^{\circ} \mathrm{C} \sim$ r.t., overnight; for 38a $\sim 38 \mathrm{i}$ and 40a 40i ArOH, $\mathrm{PPh}_{3}$, DIAD, THF, $0{ }^{\circ} \mathrm{C} \sim$ r.t., overnight; (c) $p$-TSA, MeOH, $\mathrm{H}_{2} \mathrm{O}, 20{ }^{\circ} \mathrm{C}, 0.5 \mathrm{~h}$; (d) $p$-TSA, MeOH, $\mathrm{H}_{2} \mathrm{O}, 40 \sim$ $50{ }^{\circ} \mathrm{C}, 4 \mathrm{~h}$

图式 6 穿心莲内酯衍生物 34 40 的合成

Scheme 6 Synthesis of andrographolide derivatives $34 \sim \mathbf{4 0}$

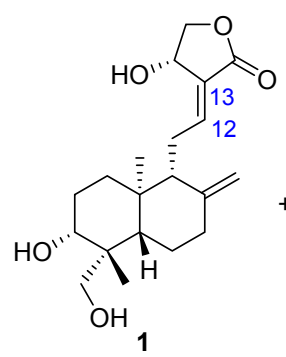

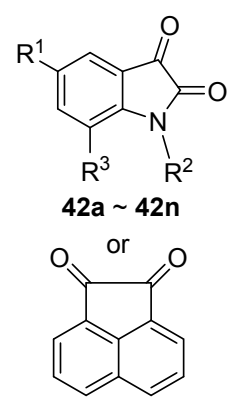

420

42a, 44a, 45a, 46a: $R^{1}=H, R^{2}=H, R^{3}=H$

42b, 44b, 45b, 46b: $R^{1}=M e, R^{2}=H, R^{3}=H$

42c, 44c, 45c, 46c: $R^{1}=O M e, R^{2}=H, R^{3}=H$

42d, 44d, 45d, 46d: $R^{1}=F, R^{2}=H, R^{3}=H$

42e, 44e, 45e, 46e: $R^{1}=C l, R^{2}=H, R^{3}=H$

42f, 44f, 45f, 46f: $R^{1}=B r, R^{2}=H, R^{3}=H$

42g, 44g, 45g, 46g: $R^{1}=I, R^{2}=H, R^{3}=H$

42h, 44h, 45h, 46h: $R^{1}=M e, R^{2}=H, R^{3}=M e$

42i, 44i,

42j, 44j, 45i, 46j: $R^{1}=H, R^{2}=P h, R^{3}=H$

42k,

42I, 44k, 45j, 46I: $R^{1}=H, R^{2}=H, R^{3}=F$

42m, 44I, 45k, 46m: $R^{1}=H, R^{2}=H, R^{3}=B r$

$42 n$,

46n: $R^{1}=H, R^{2}=H, R^{3}=1$

Reagents and conditions: (a) $100^{\circ} \mathrm{C}, 15 \mathrm{~min}, \mathrm{MW}-\mathrm{MeOH}$

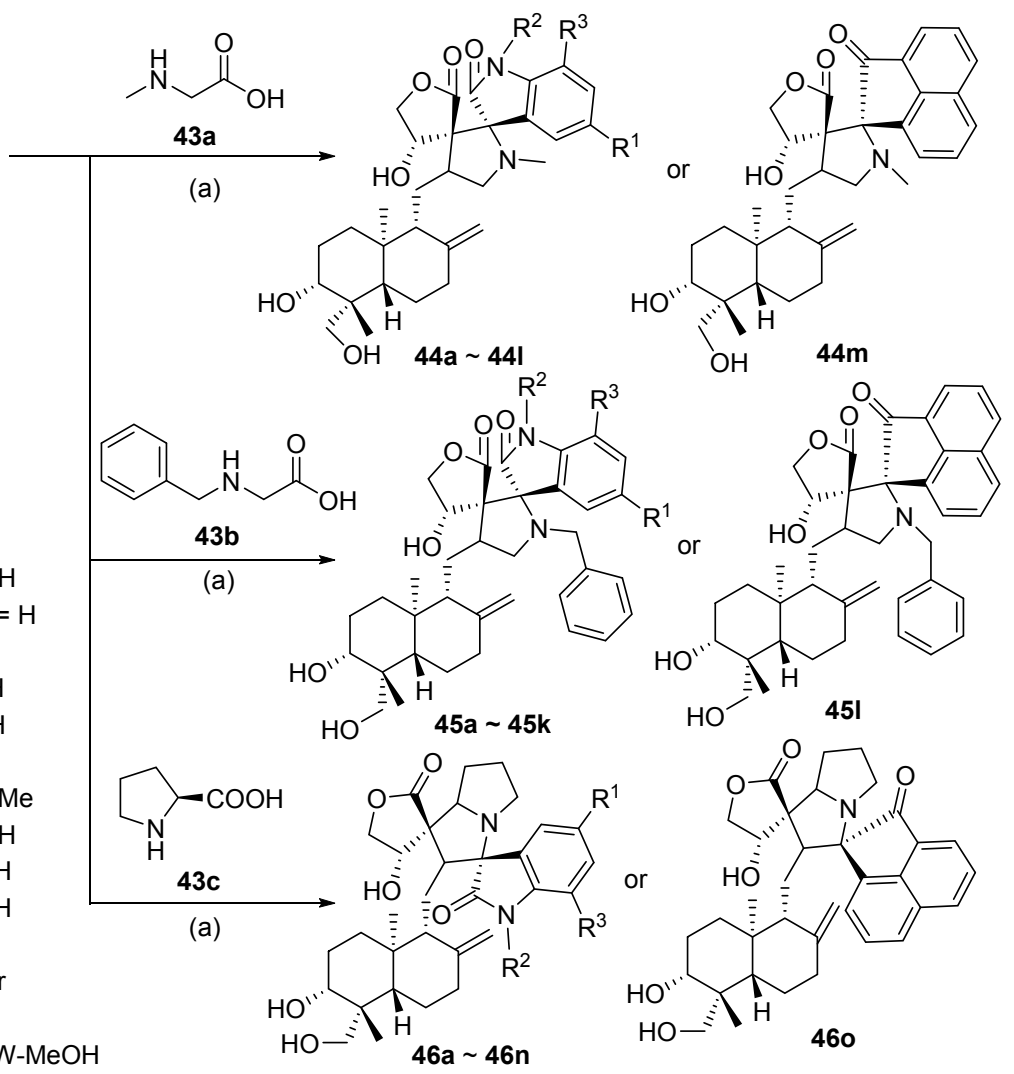

图式 7 穿心莲内酯衍生物 44 46 的合成

Scheme 7 Synthesis of andrographolide derivatives $44 \sim \mathbf{4 6}$ 


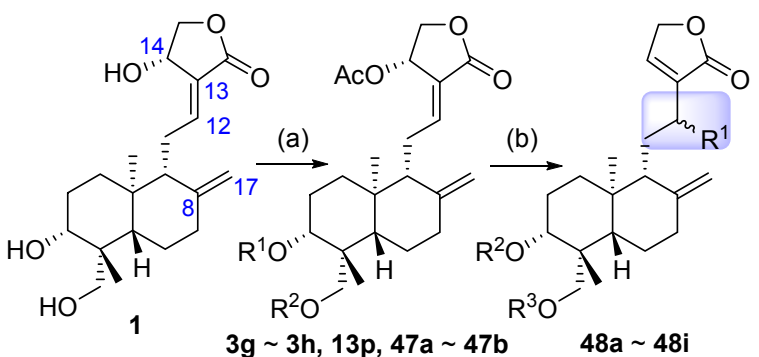

3g: $R^{1}$ and $R^{2}=$ isopropylidene

3h: $R^{1}=R^{2}=H$

13p: $R^{1}=R^{2}=A c$

47a: $R^{1}$ and $R^{2}=$ benzylidene

47b: $R^{1}$ and $R^{2}=$ phenylethylidene

(d)

(c)

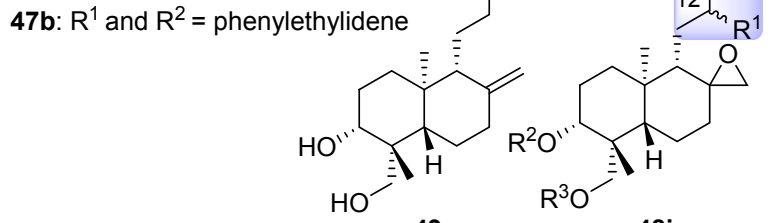

48a: $R^{1}=N H B n, R^{2}=R^{3}=A c$;

49

48j

48b: $R^{1}=\mathrm{NH}-4-\mathrm{OMeBn}, \mathrm{R}^{2}=\mathrm{R}^{3}=\mathrm{Ac}$;

48c: $R^{1}=N H B n, R^{2}=R^{3}=H$;

48d: $R^{1}=N H B n, R^{2}$ and $R^{3}=$ phenylethylidene;

48e: $R^{1}=0$-methylphenylglycino, $R^{2}$ and $R^{3}=$ phenylethylidene;

48f: $R^{1}=O$-methylprolino, $R^{2}$ and $R^{3}=$ phenylethylidene;

48g: $R^{1}=N-3^{\prime}-$--uracil, $R^{2}=R^{3}=A c$;

48h: $R^{1}=N-3^{\prime}-$-F-uracill, $R^{2}=R^{3}=H$;

48i: $R^{1}=S P h, R^{2}=R^{3}=A c$;

48j: $R^{1}=S P h, R^{2}=R^{3}=A C$

Reagents and conditions: (a) for $\mathbf{3 g}, \mathbf{4 7 a} \sim \mathbf{4 7 b}$ i) 2,2-dimethoxy propane, benzaldehyde or acetophenone, $\mathrm{C}_{6} \mathrm{H}_{6}$, DMSO, PPTS, reflux, $0.5 \mathrm{~h}$, ii) $\mathrm{Ac}_{2} \mathrm{O}, \mathrm{ZnCl}_{2}$, reflux, $45 \mathrm{~min}$; for $3 \mathrm{~h} \mathrm{i)} \mathrm{Ac}_{2} \mathrm{O}, \mathrm{ZnCl}_{2}$, reflux, $45 \mathrm{~min}$, ii) $\mathrm{AcOH} / \mathrm{H}_{2} \mathrm{O}$ (7/3), r.t., $10 \mathrm{~min}$; for $13 \mathrm{p} \mathrm{Ac}_{2} \mathrm{O}$, reflux, $5 \mathrm{~min}$; (b) for $\mathbf{4 8 a} \sim \mathbf{4 8 f}$ amines, $\mathrm{Et}_{2} \mathrm{O}$, r.t., $0.5 \mathrm{~h}$; for $\mathbf{4 8 g} \sim \mathbf{4 8 h}$ amines, hexamethyldisiloxane, imidazole, TMSOTf, DCM, r.t., $4 \mathrm{~h}$; for 48i PhSH, DCM, r.t., 48 h; (c) $m$-CPBA, TCM, $\mathrm{MeOH}$, r.t., 6 h; (d) i) $\mathrm{Ac}_{2} \mathrm{O}, \mathrm{ZnCl}_{2}$, r.t., $1 \mathrm{~h}$, ii) $\mathrm{NaBH}_{4}, \mathrm{MeOH}$, r.t., 1 h, iii) $10 \%$ $\mathrm{HCl} / \mathrm{MeOH}$, r.t., $8 \mathrm{~h}$

图式 8 穿心莲内酯衍生物 $47 \sim 49$ 的合成

Scheme 8 Synthesis of andrographolide derivatives $47 \sim 49$

吴玉林等 ${ }^{[24]}$ 结合上述 Nanduri 专利中衍生物的设计 原理，以化合物 $\mathbf{5 0}$ 为中间体合成 $\mathrm{C}-12$ 位氨基衍生物 51a 51h (Scheme 9), 并考察其抗肿瘤活性. 文章通过 MTT 实验发现化合物 51c、51d 在抑制 A549、HepG2 和 BGC-823 肿瘤细胞活性方面优于先导化合物, 其中 以对溴苯胺基衍生物 $\mathbf{5 1 d}$ 最优, $0.1 \times 10^{-4} \mathrm{~mol} / \mathrm{L}$ 浓度下 各项抑制率均接近 100\%. 实验研究发现化合物 51d 诱 导 HepG2 肿瘤细胞调亡的作用机制可能与调节 p53、 Bax 和 Bcl-2 表达有关, 并且在 H22 和 S180 荷瘤小鼠体 内实验中发现该化合物具有明显的抗肿瘤活性.

黄文龙课题组 ${ }^{[25]}$ 于 2005 年在穿心莲内酯的不同位 点引入硝酸酯, 旨在利用协同前药原理形成 NO 供体穿 心莲内酯衍生物 52a $\sim 52 \mathrm{~d} 、 53 \mathrm{a} \sim 53 \mathrm{~b} 、 54$ 以及 $55 \mathrm{a}$ (Scheme 10), 从而在体内通过释放高浓度的 $\mathrm{NO}$ 达到诱 导肿瘤细胞凋亡的效果. 其中衍生物 $52 \mathrm{a} \sim 52 \mathrm{~b}$ 是穿心

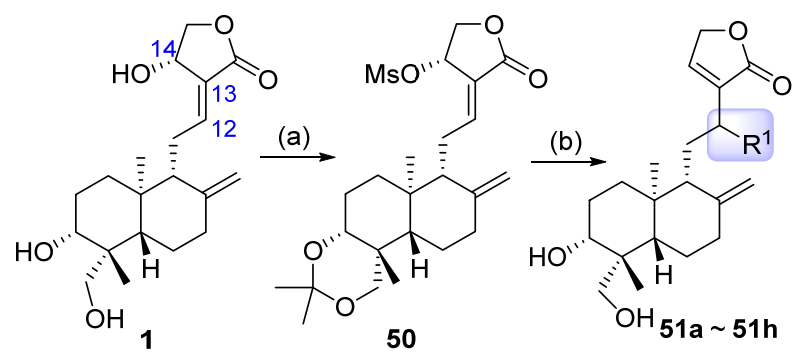

$$
\begin{array}{ll}
\text { 51a: } R^{1}=\text { anilino } & \text { 51e: } R^{1}=\text { piperazinyl } \\
\text { 51b: } R^{1}=4 \text {-toluidino } & \text { 51f: } R^{1}=\text { piperidinyl } \\
\text { 51c: } R^{1}=4 \text {-chloroanilino } & 51 \mathrm{~g}: R^{1}=\text { diethylamino } \\
\text { 51d: } R^{1}=4 \text {-bromoanilino } & \mathbf{5 1 h :} R^{1}=\text { ethanolamino }
\end{array}
$$

Reagents and conditions: (a) i) 2,2-dimethoxypropane, DCM, PPT$\mathrm{S}$, DMF, reflux, $1 \mathrm{~h}$, ii) $\mathrm{MsCl}$, TEA, DCM, r.t., $2 \mathrm{~h}$; (b) i) Amines, $\mathrm{DCM}$, reflux, $2 \mathrm{~h}$, ii) $p$-TSA, $\mathrm{MeOH}$, r.t., overnight

图式 9 穿心莲内酷衍生物 $\mathbf{5 0} \sim \mathbf{5 1}$ 的合成

Scheme 9 Synthesis of andrographolide derivatives $\mathbf{5 0} \sim \mathbf{5 1}$

莲内酯的 C-14 位烯丙醇在发烟硝酸强氧化作用下发生 迁移所得; 衍生物 $53 \mathrm{a} \sim 53 \mathrm{~b}$ 是利用硼氢化钠与 Lewis 酸联用同时还原两个双键，再发生羟基硝酸酯化得到; 而 12-硝亚甲基-14-去氧穿心莲内酯 54 则是在甲醇钠强 碱作用下，穿心莲内酯与硝基甲烷发生 Michael 加成同 时脱除一水分子所得，接着将羟基硝酸酯化形成化合物 55a. 随后, 该课题组 ${ }^{[26]}$ 以衍生物 54 为基本骨架设计并 合成 C-12 取代的去氧穿心莲内酯衍生物 $55 \sim 57$ (Scheme 10). 实验一方面直接在衍生物 54 的 C-3,19 位 二差基引入芳香族酰基，得到衍生物 $\mathbf{5 5 b} \sim \mathbf{5 5 q}$; 另一方 面先将衍生物 54 的硝基还原成伯氨并引入乙酰基形成 乙酰胺键 56, 再进一步于 C-3,19 位二羟基上同时引入 芳香族酰基, 得到衍生物 $57 \mathbf{a} \sim 57 \mathbf{j}$. 生物活性实验主要 针对 BGC-823、SMMC-7721 和 SGC-7901 三种肿瘤细 胞，研究表明：化合物 55g、55q、57a 和 57c 的对各项 细胞抑制率明显更高, 并且化合物 55f、57c 和 57d 对肝 癌细胞 SMMC-7721 的抑制率更达到接近传统抗癌药顺 铂的水平. 致炎因子 TNF- $\alpha$ 与 IL- 6 的过度表达与肿瘤发 生发展有密切联系 ${ }^{[27]}$, 黄文龙课题组 ${ }^{[28]}$ 利用 PDC 氧化 得到羟基迁移产物 58 后，合成 C-12 位羟基酯化衍生物 59a 59h (Scheme 10). 研究发现衍生物 59d 59g 抑制 脂多糖诱导小鼠巨噬细胞中 TNF- $\alpha$ 表达的能力均优于 穿心莲内酯; 在抑制 IL-6 表达活性的实验中，系列衍生 物 59a、59c $\sim 59 \mathrm{~h}$ 均有良好表现，其中以对硝基苯甲酰 化衍生物 59f 抑制能力最强, 而对甲基苯甲酰化衍生物 59e 的抑制能力虽稍逊于化合物 59f, 但对正常细胞影响 甚微，所以在篮选过程中衍生物 59e 更为理想.

徐冲与王峥涛 ${ }^{[29]}$ 于 2011 年先后发表两篇关于 12-[ $N$-酰基氨甲基]-14-去氧穿心莲内酯衍生物的合成及 


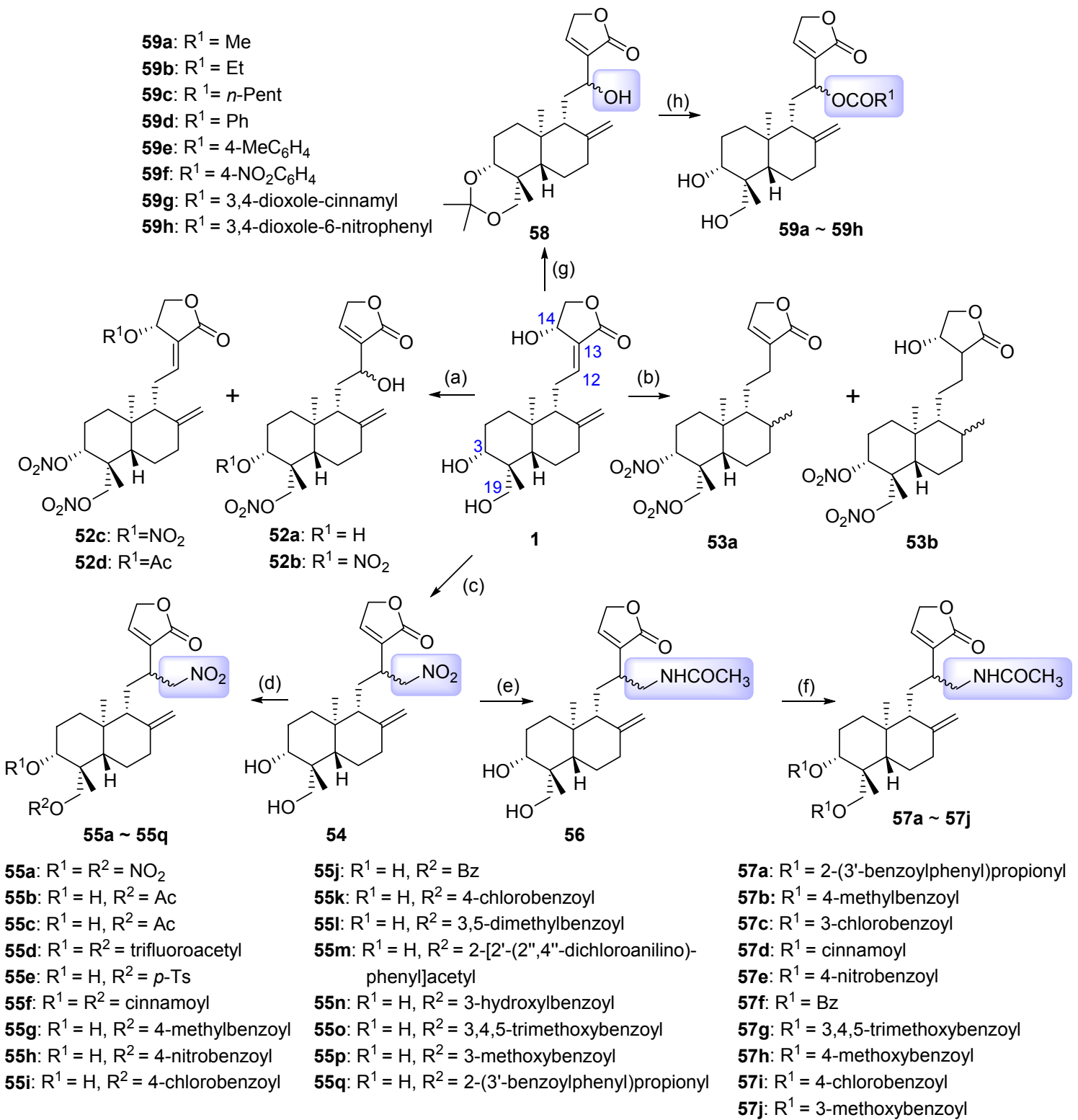

Reagents and conditions: (a) for 52a $\sim \mathbf{5 2 c}$ fuming $\mathrm{HNO}_{3}, \mathrm{Ac}_{2} \mathrm{O}, \mathrm{DCM}, 0{ }^{\circ} \mathrm{C}, 0.5 \mathrm{~h}$; for $\mathbf{5 2 d}$ i) 2,2-dimethoxypropane, $\mathrm{C}_{6} \mathrm{H}_{6}$, DMSO, PPTS, reflux, $0.5 \mathrm{~h}$, ii) $\mathrm{Ac}_{2} \mathrm{O}$, reflux, $0.75 \mathrm{~h}$, iii) $\mathrm{AcOH}, \mathrm{H}_{2} \mathrm{O}$, r.t., $0.75 \mathrm{~h}$, iv) fuming $\mathrm{HNO}_{3}, \mathrm{Ac}_{2} \mathrm{O}, \mathrm{DCM}, 0{ }^{\circ} \mathrm{C}, 0.5 \mathrm{~h}$; (b) i) $\mathrm{NaBH}_{4}, \mathrm{NiCl}_{2}-6 \mathrm{H}_{2} \mathrm{O}, \mathrm{MeOH}$, $0{ }^{\circ} \mathrm{C}, 0.5 \mathrm{~h}$, ii) fuming $\mathrm{HNO}_{3}, \mathrm{Ac}_{2} \mathrm{O}, \mathrm{DCM}, 0{ }^{\circ} \mathrm{C}, 0.5 \mathrm{~h}$; (c) $\mathrm{MeNO}_{2}$, MeONa, $\mathrm{MeOH}$, r.t., $3 \mathrm{~h}$; (d) for 55a fuming $\mathrm{HNO}_{3}, \mathrm{Ac}_{2} \mathrm{O}, \mathrm{DCM}, 0{ }^{\circ} \mathrm{C}, 0.5 \mathrm{~h}$; for $55 b \sim 55 q R^{2} \mathrm{OH}$ or $\mathrm{R}_{2}^{2} \mathrm{O}$, DCC, DMAP or TEA, r.t., $2 \sim 48 \mathrm{~h}$; (e) $\mathrm{Fe}, \mathrm{Ac}_{2} \mathrm{O}$, AcOH, r.t., $14 \mathrm{~h}$; (f) $\mathrm{R}^{1} \mathrm{COOH}$, DCC, DMAP, r.t., $48 \mathrm{~h}$; (g) i) 2,2-dimethoxypropane, DCM, PPTS, reflux, ii) PDC, DCM, reflux; (h) i) for $\mathbf{5 9 a} \sim \mathbf{5 9 c}\left(\mathrm{R}^{1} \mathrm{CO}\right)_{2} \mathrm{O}$, DCM, r.t.; for $\mathbf{5 9 d} \mathrm{R}^{1} \mathrm{COCl}$, $\mathrm{DCM}$, r.t.; for 59e $\sim 59 h \mathrm{R}^{1} \mathrm{COOH}, \mathrm{DCC}$, DMAP, DCM, r.t., ii) $\mathrm{AcOH}, \mathrm{H}_{2} \mathrm{O}$, r.t.

图式 10 穿心莲内酯衍生物 $52 \sim 59$ 的合成

Scheme 10 Synthesis of andrographolide derivatives 52 $\sim 59$

抗肿瘤活性报道. 实验以 12-氨甲基-14-去氧穿心莲内 酯 60 为中间体, 在氨基上引入不同基团形成酰胺基衍 生物 61a 61n、磺酰胺基衍生物 $62 \mathrm{a} \sim 62 \mathrm{c}$ 以及脲基衍 生物 63a 63n (Scheme 11). 文章在衍生物结构设计方 面所引入基团比较全面, 包括直链烷烃、支链烷烃、环 烷烃、含取代基苯环、苯并杂环、杂环等, 但该系列衍 生物在抗 U87、MCF-7、NA 肿瘤细胞活性方面均呈现 活性降低现象. 由此推测, 在 C-12 位引入不同取代的长 链亲水基团对穿心莲内酯的抗肿瘤作用没有帮助.

\section{3 脱水穿心莲内酯骨架衍生物}

以脱水穿心莲内酯为基础骨架(图 4), 其改造范围 包括: 双着基进行不同程度的醚化、酯化、氧化、肜化 等; C-15 不同亚烯基的取代; 端头烯键的环氧化、还原 等.

天然产物脱水穿心莲内酯(穿心莲丁素)64 (Scheme 12)最早由 Nanduri 课题组 ${ }^{[9]}$ 于 2004 年通过三羟基乙酰 化、吡啶中回流消除 C-14 位乙酯基、盐酸下脱乙酰基 
<smiles>C=C1CC[C@H]2[C@@H](CO)[C@@H](O)CC[C@]2(CC/C=C2\C(=O)OC[C@@H]2O)C1</smiles>

(a)<smiles>C=C1CC[C@H]2[C@@H](CO)[C@@H](O)CC[C@]2(C)[C@H]1C[C@H](C[N+](=O)[O-])C1=CCOC1=O</smiles>

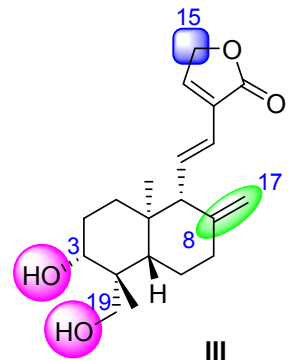

图 4 脱水穿心莲内酯骨架的结构改造
Esterification/Etherification/ Oxidation/Oximation

Substitution

Epoxidation/Reduction

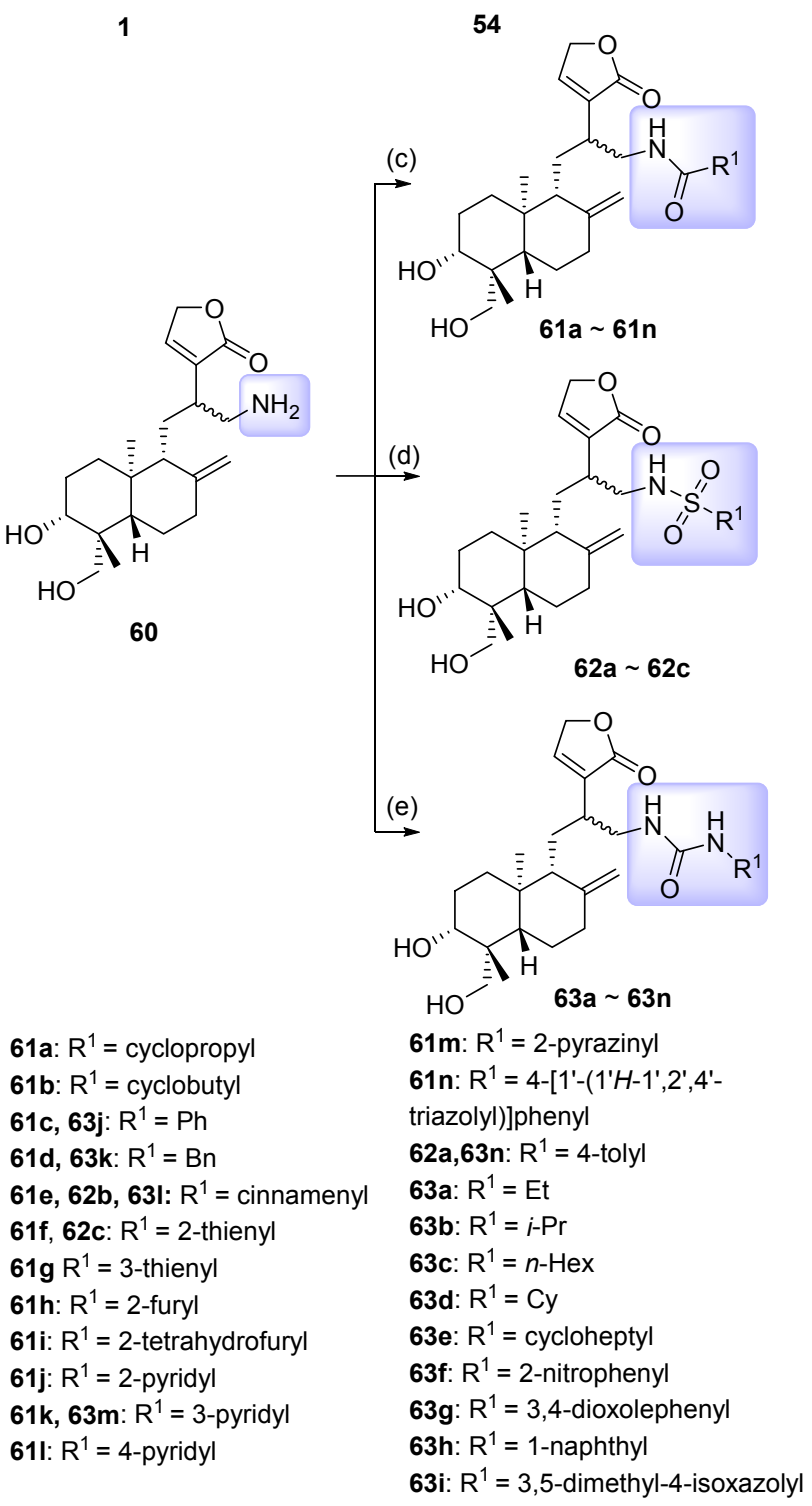

1

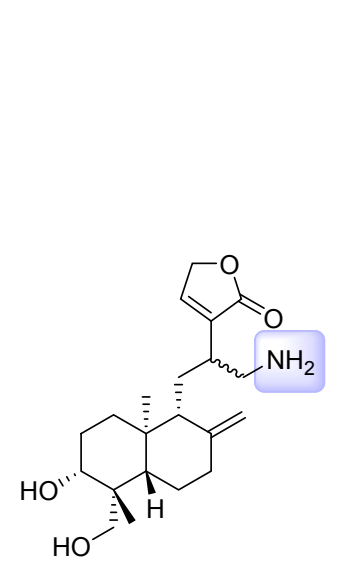

60

54

Reagent and condition: (a) $\mathrm{MeONa}, \mathrm{MeNO}_{2}, \mathrm{MeOH}$, r.t., $2.5 \mathrm{~h}$; (b) $\mathrm{Zn}, \mathrm{HCl}$, r.t., overnight; (c) $\mathrm{R}^{1} \mathrm{COOH}, \mathrm{DMF}, \mathrm{HOBt}, \mathrm{EDC}$, r.t., 3 h; (d) $\mathrm{R}^{1} \mathrm{SO}_{2} \mathrm{Cl}$, THF, $0{ }^{\circ} \mathrm{C} \sim$ r.t., overnight; (e) $\mathrm{R}^{1} \mathrm{NCO}$, THF, r.t., overnight

图式 11 穿心莲内酯衍生物 $60 \sim 63$ 的合成

Scheme 11 Synthesis of andrographolide derivatives $60 \sim 63$

共三步反应得到. 2006 年, 刘宏民课题组 ${ }^{[30]}$ 在合成穿心 莲内酯 C-3,19 位二羟基环磷酸酯衍生物 $65 \mathrm{a} \sim 65 \mathrm{c}$ (Scheme 12) 的过程中, 在 $\mathrm{Py} / \mathrm{Al}_{2} \mathrm{O}_{3}$ 体系中回流一步合成 中间体 64, 过程明显优于前者. 在抗肿瘤活性实验中, 化合物 64、65a、65b 对 CNE 和 Eca109 肿瘤细胞系的
Figure 4 Structural modification of dehydroandrographolide skeleton

抑制能力较弱. 2010 年, 刘宏民课题组 ${ }^{[31]}$ 公开专利在脱 水穿心莲内酯的 C-15 位引入亚基、C-3,19 位差基同时 引入烟酰基或单琥珀酸酰基得到衍生物 $66 \mathrm{a} \sim 66 \mathrm{~g}$ (Scheme 12), 并发现该系列衍生物可显著抑制肿瘤细 胞克隆形成、肿瘤细胞迁移作用以及肿瘤血管生成作用. 2011 年, 该课题组 ${ }^{[32]}$ 进一步考察环氧化衍生物 67 与环 氧后还原衍生物 68 (Scheme 12) 对食管癌细胞 Ec9706 的 抑制能力, 结果未发现活性.

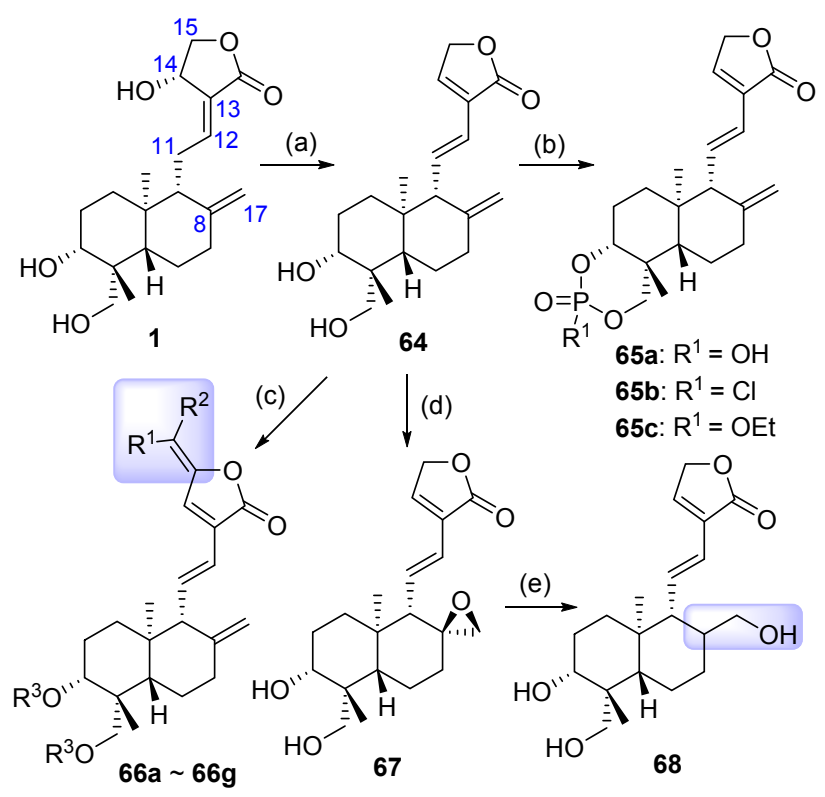

66a: $R^{1}=H, R^{2}=P h, R^{3}=H$ 66b: $R^{1}=\mathrm{H}, \mathrm{R}^{2}=4-\mathrm{FC}_{6} \mathrm{H}_{4}, \mathrm{R}^{3}=\mathrm{H}$ 66c: $\mathrm{R}^{1}=\mathrm{H}, \mathrm{R}^{2}=4-\mathrm{ClC}_{6} \mathrm{H}_{4}, \mathrm{R}^{3}=\mathrm{H}$ 66d: $R^{1}=\mathrm{H}, \mathrm{R}^{2}=4-\mathrm{BrC}_{6} \mathrm{H}_{4}, \mathrm{R}^{3}=\mathrm{H}$ 66f: $\mathrm{R}^{1}=\mathrm{H}, \mathrm{R}^{2}=4-\mathrm{ClC}_{6} \mathrm{H}_{4}$ $R^{3}=$ nicotinoyl

66e: $R^{1}=H, R^{2}=4-M O_{6} H_{4}, R^{3}=H$

66g: $\mathrm{R}^{1}=\mathrm{H}, \mathrm{R}^{2}=4-\mathrm{ClC}_{6} \mathrm{H}_{4}$, $\mathrm{R}^{3}=$ mono-succinic

Reagent and condition: (a) toluene, $\mathrm{Py}, \mathrm{Al}_{2} \mathrm{O}_{3}$, reflux, $6 \mathrm{~h}$; (b) for $66 \mathrm{a}$ $\mathrm{Py}, \mathrm{POCl}_{3}$, r.t., $24 \mathrm{~h}$; for $66 \mathrm{~b} \mathrm{Py}, \mathrm{POCl}_{3}, \mathrm{DCM}, 0{ }^{\circ} \mathrm{C}$; for $66 \mathbf{c}$ i) $\mathrm{Py}$, $\mathrm{POCl}_{3}$, DCM, $0{ }^{\circ} \mathrm{C}$, ii) $\mathrm{C}_{2} \mathrm{H}_{5} \mathrm{OH}$, Py, DMAP, reflux, $48 \mathrm{~h}$; (c) for $66 \mathbf{a} \sim$ 66e $\mathrm{R}^{2} \mathrm{CHO}$ or $\mathrm{R}_{2}^{2} \mathrm{CO}, \mathrm{MeOH}, \mathrm{Na}_{2} \mathrm{CO}_{3}$, reflux, $5 \sim 24 \mathrm{~h}$; for $66 \mathrm{ff}$ $66 \mathrm{~g}$ i) $\mathrm{R}^{2} \mathrm{CHO}, \mathrm{MeOH}, \mathrm{Na}_{2} \mathrm{CO}_{3}$, reflux, $5 \sim 24 \mathrm{~h}$, ii) TCM, nicotinic chloride or succine anhydride, TEA, reflux, $3 \mathrm{~h}$; (d) TCM, $m$-CPBA, r.t., 2 h; (e) THF, $\mathrm{H}_{2} \mathrm{SO}_{4}$, r.t., $10 \mathrm{~h}$

图式 12 穿心莲内酯衍生物 $64 \sim 68$ 的合成

Scheme 12 Synthesis of andrographolide derivatives $64 \sim 68$ 
与 TNF- $\alpha$ 和 IL-6 相同, 炎症因子 COX-2 的异常表 达同样能够促进肿瘤的发生 ${ }^{[33]} .2007$ 年, 黄文龙课题 组 ${ }^{[34]}$ 以 3-氧代脱水穿心莲内酯衍生物 69 为中间体合成 3-( $N$-取代)-酮肜脱水穿心莲内酯衍生物 $70 \mathbf{a} \sim 70 \mathrm{~h}$ (Scheme 13)，并发现衍生物 70e、70g、70h 抑制 COX-2 表达的作用均优于穿心莲内酯. 2013 年, 肖志艳等 ${ }^{[35]}$ 合 成脱水穿心莲内酯衍生物 71 72 (Scheme 13) 并考察其 抗肿瘤活性. 实验一方面于脱水穿心莲内酯的 C-3, 19 位羟基引入不同基团形成酯基，得到衍生物 $71 \mathrm{a} \sim 71 \mathrm{k}$; 另一方面将 C-3,19 位羟基与芳醛发生环合反应, 得到衍 生物 72a $\sim 72 \mathrm{f}$. 在药理活性实验中发现化合物 71b 71c、71f 和 71h 对 A549、DU145、KB 和 KB-Vin 肿瘤 细胞的抑制能力突出, 并以衍生物 71c 的各项抑制能力 最强, 而系列衍生物 72a 72f 的抑制活性普遍下降. 实 验进一步考察化合物 71c 在微管动力学上对前列腺癌细 胞 PC-3 的形态影响, 但结果并未发现细胞核转位.

\section{4 异穿心莲内酯骨架衍生物}

以异穿心莲内酯为基础骨架(图 5), 其改造范围包 括: 双羟基不同程度的醚化、酯化; C-15 不同亚烯基的 取代等; 共轭烯键的环氧化、还原等.

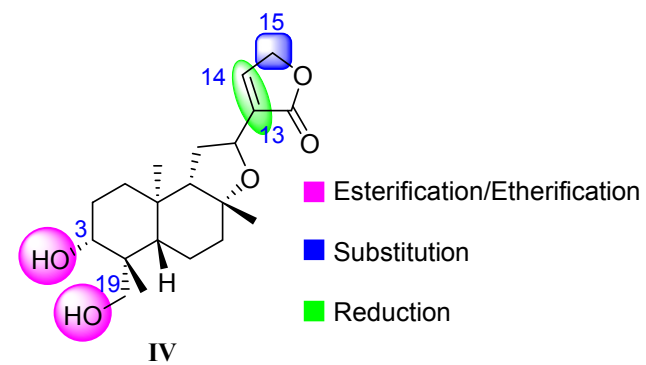

图 5 异穿心莲内酯骨架的结构改造

Figure 5 Structural modification of isoandrographolide skeleton

黄文龙课题组 ${ }^{[25]}$ 于 2005 年发现穿心莲内酯在浓盐 酸的作用下, 先发生烯丙羟基迁移, 再由 C-12 位羟基氧 对 C-8 位端头烯进行分子内加成得到异穿心莲内酯 $\mathbf{7 3}$ (Scheme 14). 该化合物在穿心莲内酯主骨架十氢荎环 上引入四氢呋喃并环, 不仅结构具有新颖性, 并且发现 对肺腺癌细胞 A549 的抑制能力高于穿心莲内酯. 该课 题组以此化合物为母核进行衍生化 (Scheme 14): 引入 $\mathrm{NO}$ 供体, 将羟基硝酸酯化形成化合物 74a、 $\mathbf{7 4 b} \mathbf{b}^{[25]}$; 在 C-3,19 位同时引入草酸酯或酰胺酯得到系列衍生物 $75 \mathbf{a} \sim 75 \mathbf{u}^{[36]}$; 在 C-3,19 位同时或分别引入烷酰基、芳酰 基、亚砜基或芳烷基得到衍生物 $\mathbf{7 6 a} \sim 76 \mathrm{k}^{[28,34]}$; 内酯环 内双键在 $\mathrm{NaBH}_{4} / \mathrm{NiCl}_{2}$ 的作用下还原得到衍生物 $77^{[37]}$.
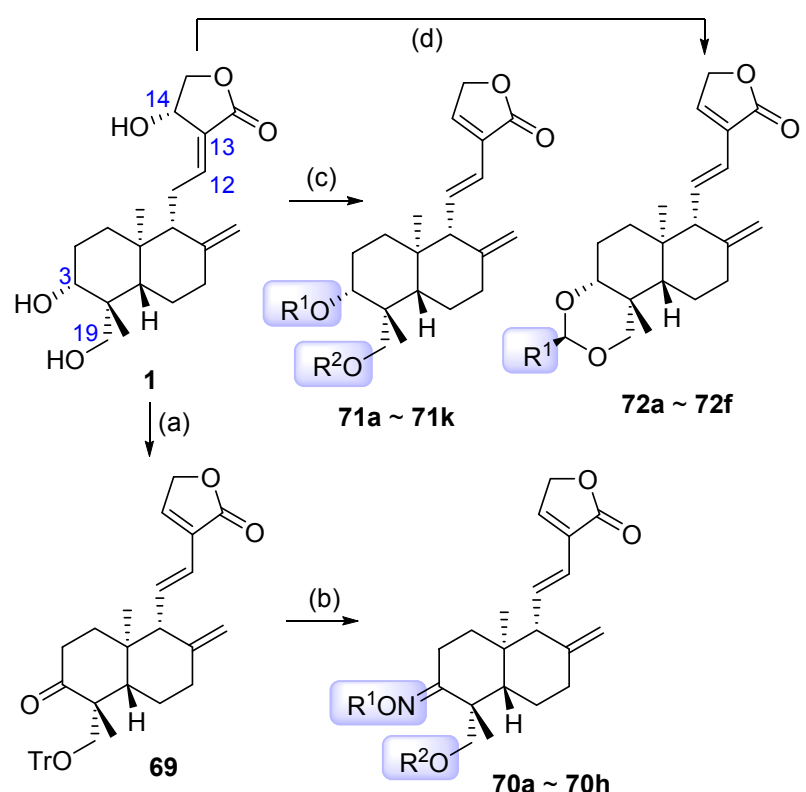

70a: $R^{1}=R^{2}=H ; 70 b: R^{1}=M e, R^{2}=H ; 70 c: R^{1}=R^{2}=A c ;$

70d: $R^{1}=R^{2}=$ propionyl; 70e: $R^{1}=R^{2}=$ Bz; 70f: $R^{1}=R^{2}=$ cinnamoyl;

70g: $R^{1}=4-C I B z, R^{2}=H ; 70 h: R^{1}=$ benzylcarbonyl, $R^{2}=H$

71a: $R^{1}=R^{2}=$ nicotinoyl

71b: $R^{1}=R^{2}=2$-pyrazinylcarbonyl

71c: $R^{1}=R^{2}=N$-methyl-4-piperidylcarbonyl

71d: $R^{1}=R^{2}=3$-dimethylaminopropionyl

71e: $R^{1}=R^{2}=$ 2-dimethylaminoacetyl

71f: $R^{1}=R^{2}=N$-Boc-pyrrolidinyl-2-carbonyl

71g: $R^{1}=R^{2}=3-(4-$ morpholinyl)propionyl

71h: $R^{1}=R^{2}=$ lipoyl

71i: $R^{1}=H, R^{2}=N$-Boc-pyrrolidinyl-2-carbonyl

71j: $R^{1}=H, R^{2}=3-(4-$ morpholinyl)propionyl

71k: $R^{1}=H, R^{2}=$ lipoyl

72a: $R^{1}=4$-nitrophenyl; 72b: $R^{1}=4$-trifluoromethyphenyl

72c: $R^{1}=4$-hydroxyphenyl; 72d: $R^{1}=4$-methoxyphenyl

72e: $R^{1}=4$-dimethylaminophenyl; 72f: $R^{1}=2$-furyl

Reagents and conditions: (a) i) $\mathrm{Al}_{2} \mathrm{O}_{3}, \mathrm{Py}$, reflux, ii) $\mathrm{TrCl}, \mathrm{NMM}$ DCM, r.t., iii) PDC, DCM, r.t.; (b) for $70 a \sim 70 b$ i) $\mathrm{NH}_{2} \mathrm{OH}-\mathrm{HCl}$ or $\mathrm{NH}_{2} \mathrm{OMe}-\mathrm{HCl}$, Py, $40{ }^{\circ} \mathrm{C}$, ii) $\mathrm{HCOOH}$, DCM, r.t.; for 70c $\sim 70$ f i) $\mathrm{NH}_{2} \mathrm{OH}-\mathrm{HCl}, \mathrm{Py}, 40{ }^{\circ} \mathrm{C}$, ii) $\mathrm{HCOOH}$, DCM, r.t., iii) $\mathrm{R}_{2}^{1} \mathrm{O}$ or $\mathrm{R}^{1} \mathrm{Cl}$ or $\mathrm{R}^{1} \mathrm{OH}$, DMAP, DCM, r.t.; for $\mathbf{7 0 g} \sim \mathbf{7 0 h}$ i) $\mathrm{NH}_{2} \mathrm{OH}-\mathrm{HCl}$, Py, $40{ }^{\circ} \mathrm{C}$, ii) $\mathrm{R}^{1} \mathrm{OH}$, DMAP, DCM, r.t., iii) $\mathrm{HCOOH}$, DCM, r.t.; (c) i) $\mathrm{Py}, \mathrm{Al}_{2} \mathrm{O}_{3}$, reflux, 8 10 h, ii) $\mathrm{R}^{2} \mathrm{Cl}$, EDCl, DMAP, DCM, r.t.; (d) i) $\mathrm{Py}, \mathrm{Al}_{2} \mathrm{O}_{3}$, reflux, $8 \sim 10 \mathrm{~h}$, ii) $\mathrm{R}^{1} \mathrm{CHO}, \mathrm{H}_{2} \mathrm{SO}_{4}(0.5 \%)$, THF, reflux, $2 \sim 5 \mathrm{~h}$

图式 13 穿心莲内酯衍生物 69 72 的合成

Scheme 13 Synthesis of andrographolide derivatives 69 72

生物活性方面，化合物 75m 在对早幼粒白血病 HL60 的 抑制率与穿心莲内酯相同，而引入的长链基团的化合物 75t、75u 的抗肿瘤活性无明显改善; 衍生物 76c、76f 抑制脂多糖诱导小鼠巨噬细胞中 TNF- $\alpha$ 表达的能力均 优于穿心莲内酯, 其中以 C-3 位羟基苯甲酰化衍生物 76f 抑制能力最强. 衍生物 76e $\sim 76 \mathrm{~g} 、 76 \mathrm{j} \sim 76 \mathrm{k}$ 在抑制 脂多糖诱导小鼠巨噬细胞 COX-2 表达的作用明显, 其 中以 C-19 位羟基三苯甲基化衍生物 76k 抑制能力最强, 但对正常细胞的 COX-2 表达也有很大影响. 


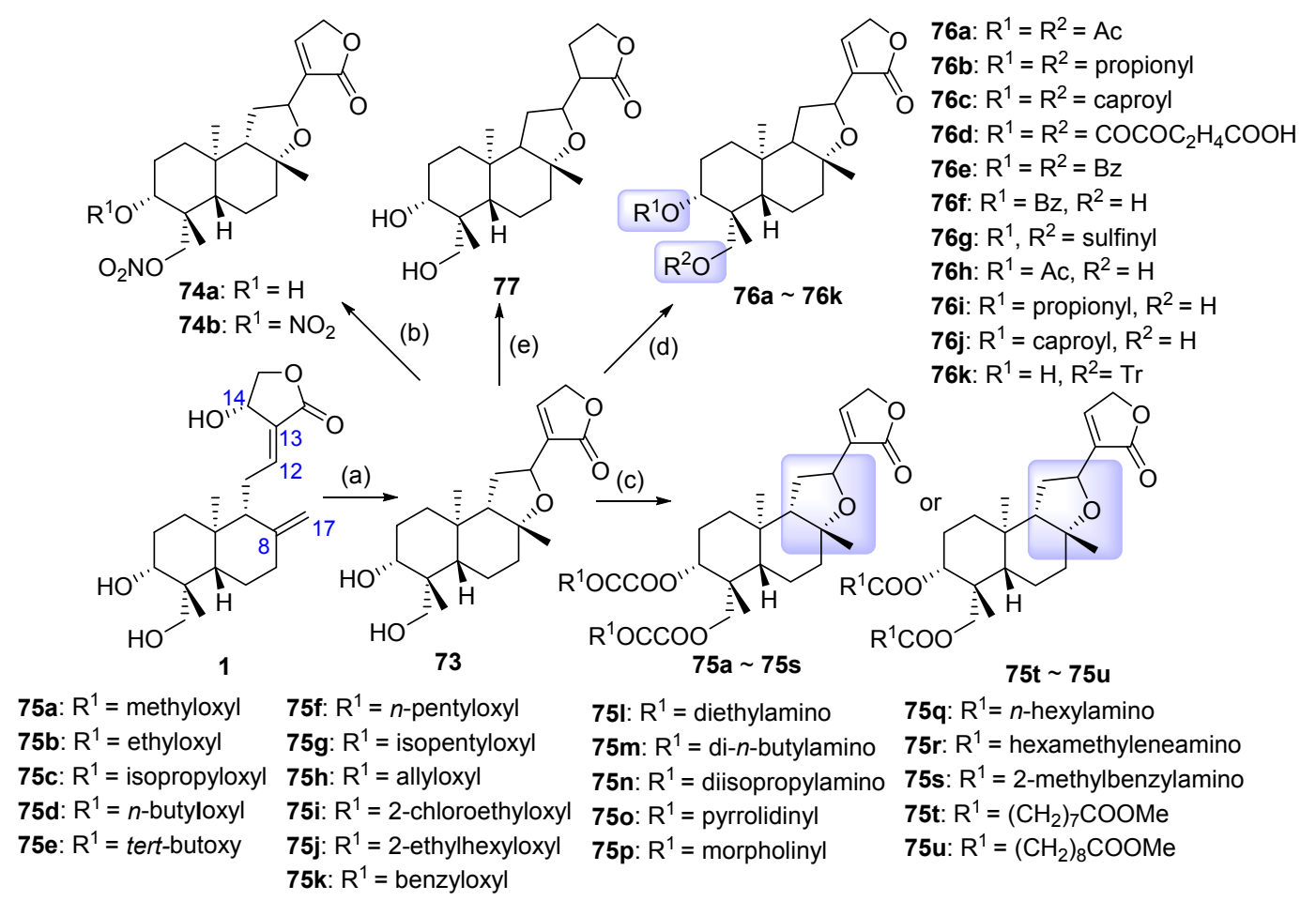

Reagents and conditions: (a) cont. $\mathrm{HCl}$, r.t., overnight; (b) fuming $\mathrm{HNO}_{3}, \mathrm{Ac}_{2} \mathrm{O}, \mathrm{DCM}, 0{ }^{\circ} \mathrm{C}, 0.5 \mathrm{~h}$; (c) for $\mathbf{7 5 a} \sim 75 \mathrm{~s}$ i) $\mathrm{ClOCCOCl}$, r.t., $5 \mathrm{~h}$, ii) $\mathrm{R}^{1} \mathrm{H}$, TEA, r.t., overnight; for $\mathbf{7 5 t} \sim \mathbf{7 5 u}$ i) $\mathrm{ClOC}\left(\mathrm{CH}_{2}\right)_{7} \mathrm{COCl}$ or $\mathrm{ClOC}\left(\mathrm{CH}_{2}\right)_{8} \mathrm{COCl}$, r.t., 5 h, ii) $\mathrm{MeOH}$, TEA, r.t., 6 h; (d) for $\mathbf{7 6 a} \sim 75 \mathbf{d ~ R}{ }_{2}^{1} \mathrm{O}, \mathrm{DCM}$, r.t.; for $\mathbf{7 6 e} \sim \mathbf{7 6 f} \mathrm{R}^{1} \mathrm{Cl}$, DCM, reflux; for $\mathbf{7 6 g ~ S O C l}$, reflux; for $\mathbf{7 6 h} \sim \mathbf{7 6 j}$ i) $\mathrm{TrCl}$, NMM, DCM, r.t., ii) $\mathrm{R}_{2}^{1} \mathrm{O}$, DMAP, DCM, r.t., iii) $\mathrm{HCOOH}$, DCM, r.t.; for $76 \mathbf{k} \mathrm{TrCl}, \mathrm{NMM}$, DCM, r.t.; (e) $\mathrm{NaBH}_{4}, \mathrm{NiCl}_{2}-6 \mathrm{H}_{2} \mathrm{O}, 0{ }^{\circ} \mathrm{C}, 0.5 \mathrm{~h}$

图式 14 穿心莲内酯衍生物 $73 \sim 77$ 的合成

Scheme 14 Synthesis of andrographolide derivatives $73 \sim 77$

2007 年, 刘宏民课题组 ${ }^{[38]}$ 设计合成异穿心莲内酯 类似物 78 81 (Scheme 15), 并考察其肿瘤活性. 实验 将穿心莲内酯端头烯键环氧化, 在硫酸的作用下得到衍 生物 78a，再与多聚甲醛合成衍生物 78b; 3,19-亚氧基8,17 -环氧穿心莲内酯在 $p$ - $\mathrm{TsOH}$ 的作用下得到衍生物 79a, 或在 $\mathrm{ZnCl}_{2} / \mathrm{MeOH}$ 体系中得到衍生物 79b; 将化合 物 58 进行烯键环氧化, 于 $\mathrm{H}_{3} \mathrm{PO}_{4}$ 体系中得到衍生物 80a, 再进一步羟基乙酰化得到衍生物 80b. 接着, 实验首次 在异穿心莲内酯类似物的基础上合成 C-15 位芳醛加成 衍生物 81a 81d. 生物实验中, C-15 位亚基取代后的衍 生物对肿瘤细胞 CNE 与 Ea109 的抑制能力有一定提高. 课题组 ${ }^{[32]}$ 于 2011 年进一步考察衍生物 78a、78b 对食管 癌细胞 Ec9706 的活性, 但均未发现抑制能力.

\section{12-环替代的穿心莲内酯骨架衍生物}

上述四种骨架衍生物均保留内酯环或内酯结构(图 6), 本节以 12-环替代的穿心莲内酯(或异穿心莲内酯)为 基本骨架, 其改造重点在于内酯的开环、还原以及内酯 环被替代, 并在此基础上对双羟基进行不同程度的醚 化、酯化、氧化等.

2004 年, Nanduri 课题组 ${ }^{[9]}$ 首先在 $\mathrm{NaOH}$ 作用下使得

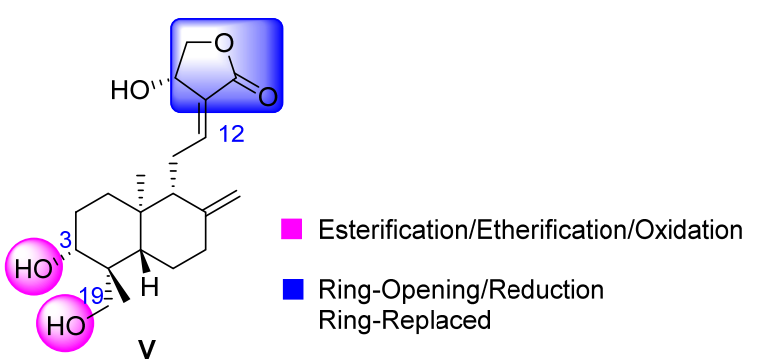

图 6 12-环替代的穿心莲内酯骨架的结构改造

Figure 6 Structural modification of 12-ring replaced andrographolide skeleton

内酯开环得到衍生物 82 , 该化合物在先导结构中增加 了一个羟基和一个羧基，不仅提高水溶性，而且化合物 对肾癌细胞 A498 具有一定抑制能力. 同年，该课题组 ${ }^{[8]}$ 进一步合成芳环替代内酯环衍生物 83 93 (Scheme 16): 先将 C-12, 13 位双键切割氧化得到醛基产物 18, 再引入 不同芳环. 合成过程涉及 Reformatsky 反应、Wittig 反应 以及 LDA 还原反应等, 改造难度明显增加, 对后续结构 改造工作提出更高的要求. 其中，苯环替代衍生物 $\mathbf{8 8 b}$ 和嘧啶胺环替代衍生物 91 在前列腺肿瘤细胞 DU145 上 的 $\mathrm{GI}_{50}$ 值达到 0.17 和 $0.2 \mu \mathrm{mol} / \mathrm{L}$ ，抑制效果显著; 嘧啶 

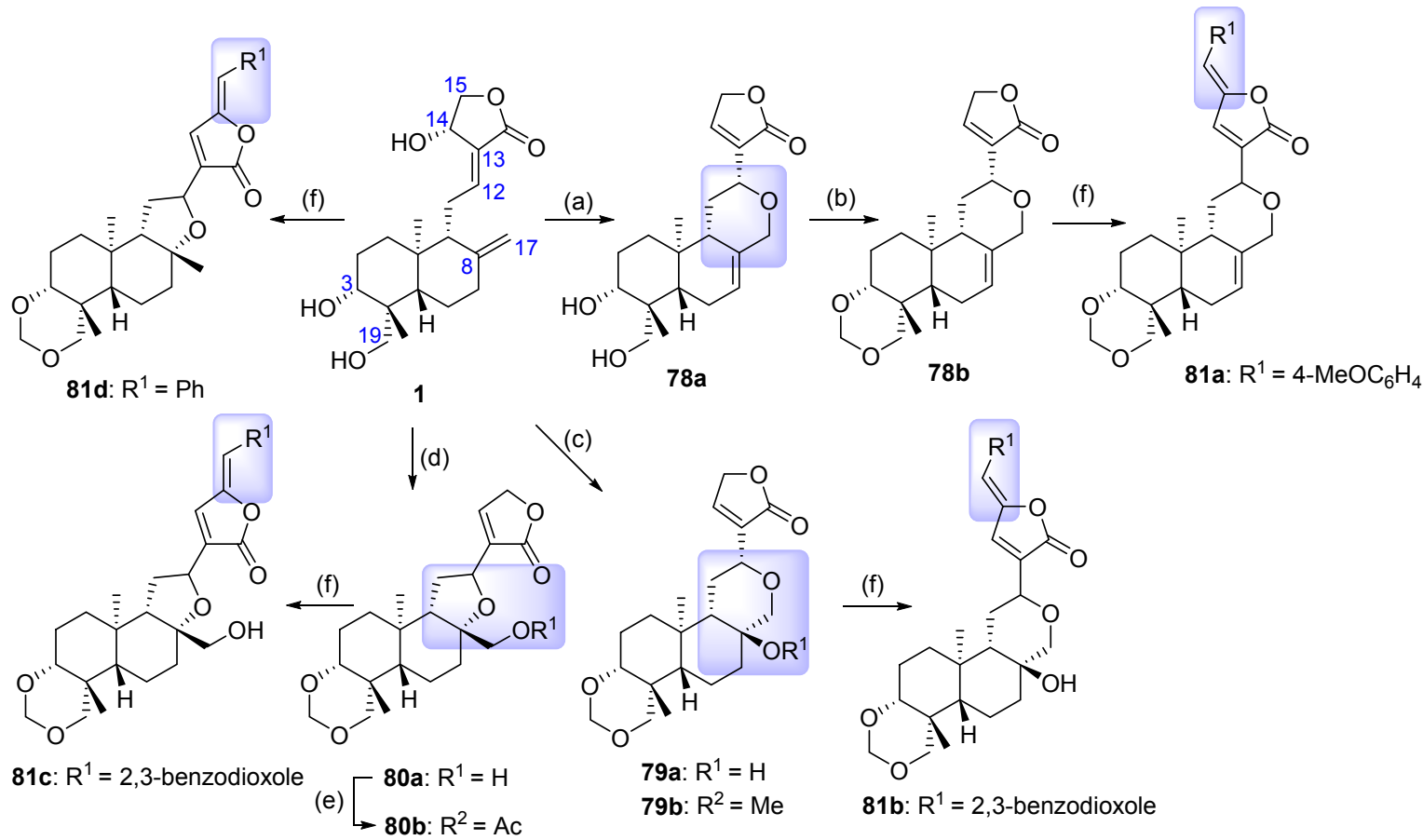

Reagent and condition: (a) i) TCM, $m$-CPBA, r.t., 2 h, ii) THF, $\mathrm{H}_{2} \mathrm{SO}_{4}$, r.t., $10 \mathrm{~h}$; (b) paraformaldehyde, THF, $\mathrm{H}_{2} \mathrm{SO}_{4}$, reflux, 1 h; (c) i) paraformaldehyde, THF, $\mathrm{H}_{2} \mathrm{SO}_{4}$, reflux, $1 \mathrm{~h}$, ii) TCM, $m$-CPBA, r.t., $2 \mathrm{~h}$; for 79a iii) $p$-TsOH (cat.), THF, $\mathrm{H}_{2} \mathrm{O}$, r.t., 20 h; for $79 \mathrm{~b}$ iii) $\mathrm{ZnCl} 2, \mathrm{MeOH}^{2}$, r.t., 20 h; (d) i) paraformaldehyde, THF, $\mathrm{H}_{2} \mathrm{SO}_{4}$, reflux, $1 \mathrm{~h}$, ii) PDC, DCM, reflux, $5 \mathrm{~h}$, iii) TCM, $m$-CPBA, r.t., $2 \mathrm{~h}$, iv) $1 \% \mathrm{H}_{3} \mathrm{PO}_{4}-\mathrm{THF}, 60{ }^{\circ} \mathrm{C}, 5 \mathrm{~h}$; (e) $\mathrm{Ac} 2 \mathrm{O}$, TEA, TCM, r.t., 3 h; (f) for 81a anisic aldehyde, Py, EtOH, reflux, $7 \mathrm{~h}$; for $\mathbf{8 1 b}$ piperonyl aldehyde, $\mathrm{K}_{2} \mathrm{CO}_{3}$, THF, r.t., $20 \mathrm{~h}$; for $81 \mathrm{c}$ piperonyl aldehyde, EDA, MeCN, reflux, $4 \mathrm{~h}$; for $\mathbf{8 1 d}$ i) cont. $\mathrm{HCl}$, r.t., overnight, ii) paraformaldehyde, $\mathrm{THF}, \mathrm{H}_{2} \mathrm{SO}_{4}$, reflux, $1 \mathrm{~h}$, iii) benzaldehyde, $\mathrm{Na}_{2} \mathrm{CO}_{3}, 1,4$-dioxane, $30{ }^{\circ} \mathrm{C}, 5 \mathrm{~h}$

图式 15 穿心莲内酯衍生物 $78 \sim 81$ 的合成

Scheme 15 Synthesis of andrographolide derivatives $\mathbf{7 8} \sim \mathbf{8 1}$

胺环替代衍生物 93 对乳腺肿瘤细胞 $\mathrm{MCF}-7$ 的 $\mathrm{GI}_{50}$ 值达 到 $0.01 \mu \mathrm{mol} / \mathrm{L}$. 在此研究基础上, 本文认为内酯环结构 并非穿心莲内酯衍生物发挥抗肿瘤作用的必要结构.

黄文龙课题组在考察穿心莲内酯衍生物对 COX-2 抑制作用的过程中合成多种开环衍生物 $94 \sim 99^{[37]}$ (Scheme 17). 实验以衍生物 8 或 77 为中间体, 在 $\mathrm{HCl} /$ $\mathrm{MeOH}$ 作用下得到内酯开环-羟基氯代-羧基甲酯化衍 生物 94 或 97, 再与胺经酰化反应首次得到内酰胺环衍 生物 95a $\sim 95 \mathrm{c}$ 或 $98 \mathrm{a} \sim 98 \mathrm{e}$; 以衍生物 8 为中间体, 在 $n-\mathrm{BuNH}_{2} / \mathrm{KOH}$ 体系中得到开环-酰胺化衍生物 96; 异穿 心莲内酯 73 在 $\mathrm{HCl} / \mathrm{MeOH}$ 作用下醇解得到衍生物 99a, 再与胺合成衍生物 99b. 活性方面, 衍生物 97、98a 抑制 脂多糖诱导小鼠巨噬细胞 COX-2 表达的能力优于先导 化合物.

Nanduri 课题组 ${ }^{[39]}$ 利用由一种天然产物通过结构改 造得到另一天然产物结构类似物的设计思想, 将穿心莲 内酯的结构修饰得到天然产物(一)-limonidilactone 类似 物 100 110 (Scheme 18). (一)-limonidilactone 与穿心莲 内酯同属半日花烷二萜类天然产物, 其化学结构与药理 活性也与穿心莲内酯类似, (十)-limonidilactone 已通过 (一)-limonidilactone 合成得到 ${ }^{[40]}$. 实验以穿心莲内酯为
原料，首先在 $\mathrm{PDC}$ 氧化剂的作用合成中间体 12-TBSO-14-去氧穿心莲内酯 100, 然后将内酯通过 DIBAL-H 还原生成呋喃环化合物 104, 再经氧化、还原 生成化合物 107 , 成功将内酯环翻转形成与 limonidilactone 内酯环相同的结构, 接着在 C-7 位引入 羟基并发生烯丙羟基迁移，最后 TEMPO 氧化将 C-12 和 C-17 环合形成 $\alpha, \beta$-不饱和-1,5-戊内酯, 至此得到新的与 limonidilactone 结构类似的穿心莲内酯衍生物 110; 另一 方面，文献以类似方法得到与穿心莲内酯的内酯方向保 持一致的 limonidilactone 类似物 103. 该研究不仅丰富 了穿心莲内酯衍生物的基本骨架, 而且提供了一种全新 的衍生物设计思路.

继 Nanduri 课题组之后, 张大永课题组 ${ }^{[41]}$ 再次应用 上述设计思想, 于 2012 年公开专利以穿心莲内酯为原 料合成 3-取代型岩大戟内酯类化合物(Scheme 19). 现代 医学与中医学研究均发现天然产物岩大戟内酯 (Jolkinolide A、Jolkinolide B) 类化合物具有多种生物活 性, 其中以抗肿瘤效果最为明显 ${ }^{[42]}$, 专利结合两者药理 作用拟合成一系列抗肿瘤活性更高的衍生物. 实验以穿 心莲内酯为原料, 经三羟基乙酰化、还原、双键切割得 到中间体 111, 再经过数次分子内环合、双键环氧化, 最 


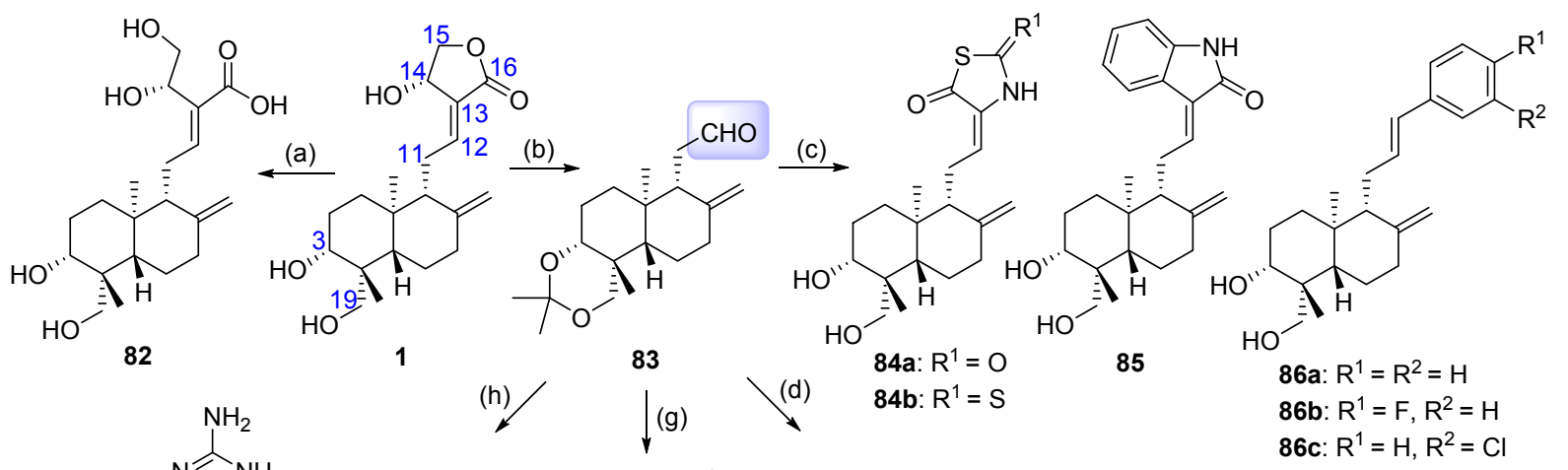

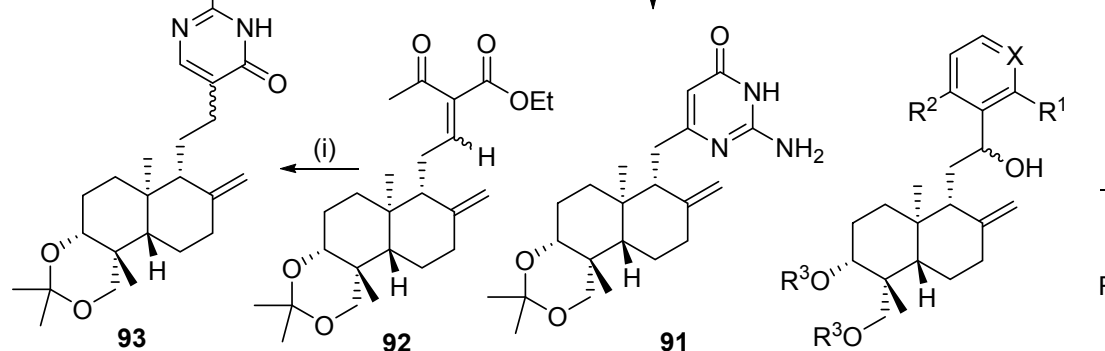

87a: $X=N, R^{1}=C l, R^{2}=H, R^{3}=$ isopropylidene 87b: $X=C, R^{1}=R^{2}=O M e, R^{3}=$ isopropylidene

88a: $X=N, R^{1}=C l, R^{2}=H, R^{3}=H$

(e) $\leftarrow$ 87a 87b

$\rightarrow 88 a \sim 88 b$

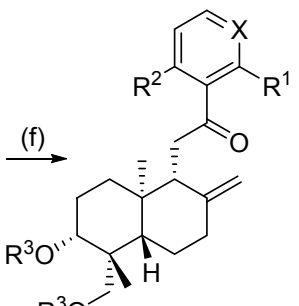

$\mathrm{R}^{3} \mathrm{O}^{-}$

(e) $\longrightarrow \begin{array}{r}89 \\ -90\end{array}$

89: $X=N, R^{1}=C l, R^{2}=H, R^{3}=$ isopropylidene

88b: $X=C, R^{1}=R^{2}=O M e, R^{3}=H$

90: $X=N, R^{1}=C l, R^{2}=H, R^{3}=H$

Reagents and conditions: (a) i) aq. $\mathrm{NaOH}$, reflux, $1 \mathrm{~h}$, ii) aq. $\mathrm{HCl}$, r.t.; (b) i) 2,2-dimethoxypropane, $\mathrm{PPTS}, \mathrm{C}_{6} \mathrm{H}_{6}$, reflux, ii) $\mathrm{Ac} \mathrm{C}_{2} \mathrm{O}$, TEA, $\mathrm{DCM}$, r.t., iii) DMAP, DCM, r.t., iv) aq. $\mathrm{KMnO}_{4}$, THF, r.t; (c) for $\mathbf{8 4} \sim \mathbf{8 5}$ i) rhodanine or thiazolidinedione or oxindole, $\beta$-alanine, $\mathrm{C}_{6} \mathrm{H}_{6}$, reflux, ii) $\mathrm{AcOH} / \mathrm{H}_{2} \mathrm{O}$ $(V / V=7 / 3)$, r.t.; for 86 i) Wittig salts of substituted benzyl bromides, $\mathrm{NaH}, \mathrm{C}_{6} \mathrm{H}_{6}$, r.t., ii) $\mathrm{AcOH} / \mathrm{H}_{2} \mathrm{O}(V / V=7 / 3)$, r.t.; (d) substituted aromatic nucleus, LDA, $-78{ }^{\circ} \mathrm{C}$; (e) $\mathrm{AcOH} / \mathrm{H}_{2} \mathrm{O}\left(V / V=7 / 3\right.$ ), r.t.; (f) PDC, DCM, r.t.; (g) i) $\mathrm{BrCH}_{2} \mathrm{CO}_{2} \mathrm{C}_{2} \mathrm{H}_{5}, \mathrm{Zn}, \mathrm{C}_{6} \mathrm{H}_{6}$, reflux, ii) PDC, DCM, r.t., iii) guanidinium chloride, $\mathrm{NaOMe}, \mathrm{MeOH}$, reflux; (h) ethyl acetoacetate, $\mathrm{TiCl}_{4}, \mathrm{Py}$; (i) i) $\mathrm{NaBH}_{4}, \mathrm{MeOH}$, ii) PDC, DCM, r.t., iii) guanidine hydrochloride, $\mathrm{NaOMe}, \mathrm{MeOH}$, reflux

图式 16 穿心莲内酯衍生物 $82 \sim 93$ 的合成

Scheme 16 Synthesis of andrographolide derivatives $82 \sim 93$

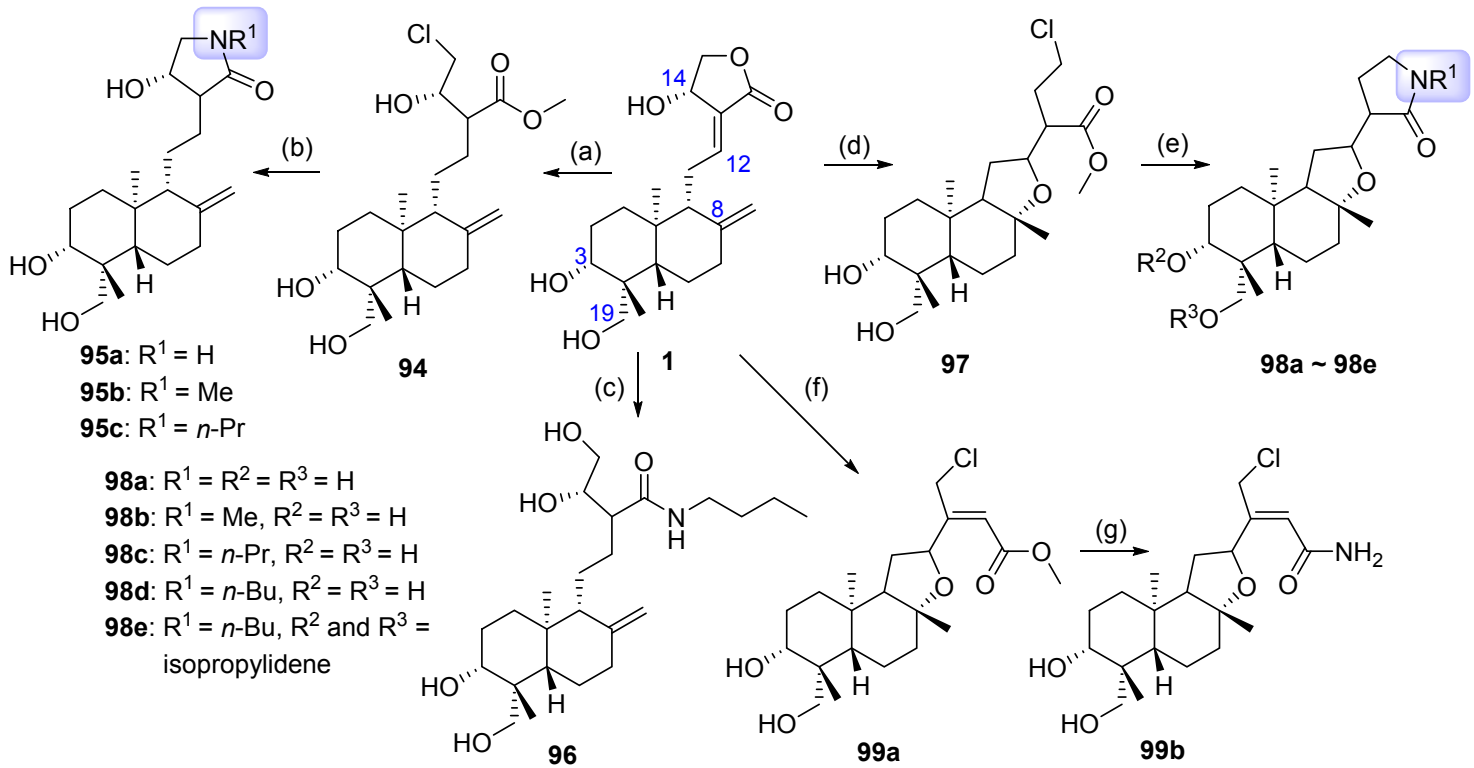

Reagents and conditions: (a) i) $\mathrm{NaBH}_{4}, \mathrm{NiCl}_{2}-6 \mathrm{H}_{2} \mathrm{O}, 0{ }^{\circ} \mathrm{C}, 0.5 \mathrm{~h}$, ii) $\mathrm{HCl}(\mathrm{g}), \mathrm{MeOH}, 70{ }^{\circ} \mathrm{C}, 6 \mathrm{~h}$; (b) $\mathrm{NH}_{2} \mathrm{R}^{1}$, $\mathrm{MeOH}, 40{ }^{\circ} \mathrm{C}$, overnight; (c) i) $\mathrm{NaBH}_{4}, \mathrm{NiCl}_{2}-6 \mathrm{H}_{2} \mathrm{O}, 0{ }^{\circ} \mathrm{C}, 0.5 \mathrm{~h}$, ii) $n-\mathrm{BuNH}_{2}, \mathrm{DMF}, \mathrm{KOH}, 90{ }^{\circ} \mathrm{C}$; (d) i) cont. $\mathrm{HCl}$, r.t., overnight, ii) $\mathrm{NaBH}_{4}, \mathrm{NiCl}_{2}-6 \mathrm{H}_{2} \mathrm{O}, 0{ }^{\circ} \mathrm{C}, 0.5 \mathrm{~h}$, iii) $\mathrm{HCl}(\mathrm{g})$, $\mathrm{MeOH}, 70{ }^{\circ} \mathrm{C}, 6 \mathrm{~h}$; (e) for $\mathbf{9 8 a} \sim \mathbf{9 8 d ~} \mathrm{NH}_{2} \mathrm{R}^{1}, \mathrm{MeOH}, 40{ }^{\circ} \mathrm{C}$, overnight; for 98e i) $\mathrm{NH}_{2} \mathrm{R}^{1}, \mathrm{MeOH}, 40{ }^{\circ} \mathrm{C}$, overnight, ii) 2,2-dimethoxypropane, PPTS, DCM, reflux, $1 \mathrm{~h}$; (f) $\mathrm{HCl}(\mathrm{g}), \mathrm{MeOH}, 70{ }^{\circ} \mathrm{C}, 6 \mathrm{~h}$; (g) $\mathrm{NH}_{3}-\mathrm{H}_{2} \mathrm{O}, \mathrm{MeOH}, 40{ }^{\circ} \mathrm{C}$, overnight

图式 17 穿心莲内酯衍生物 94 99 的合成

Scheme 17 Synthesis of andrographolide derivatives $94 \sim 99$ 


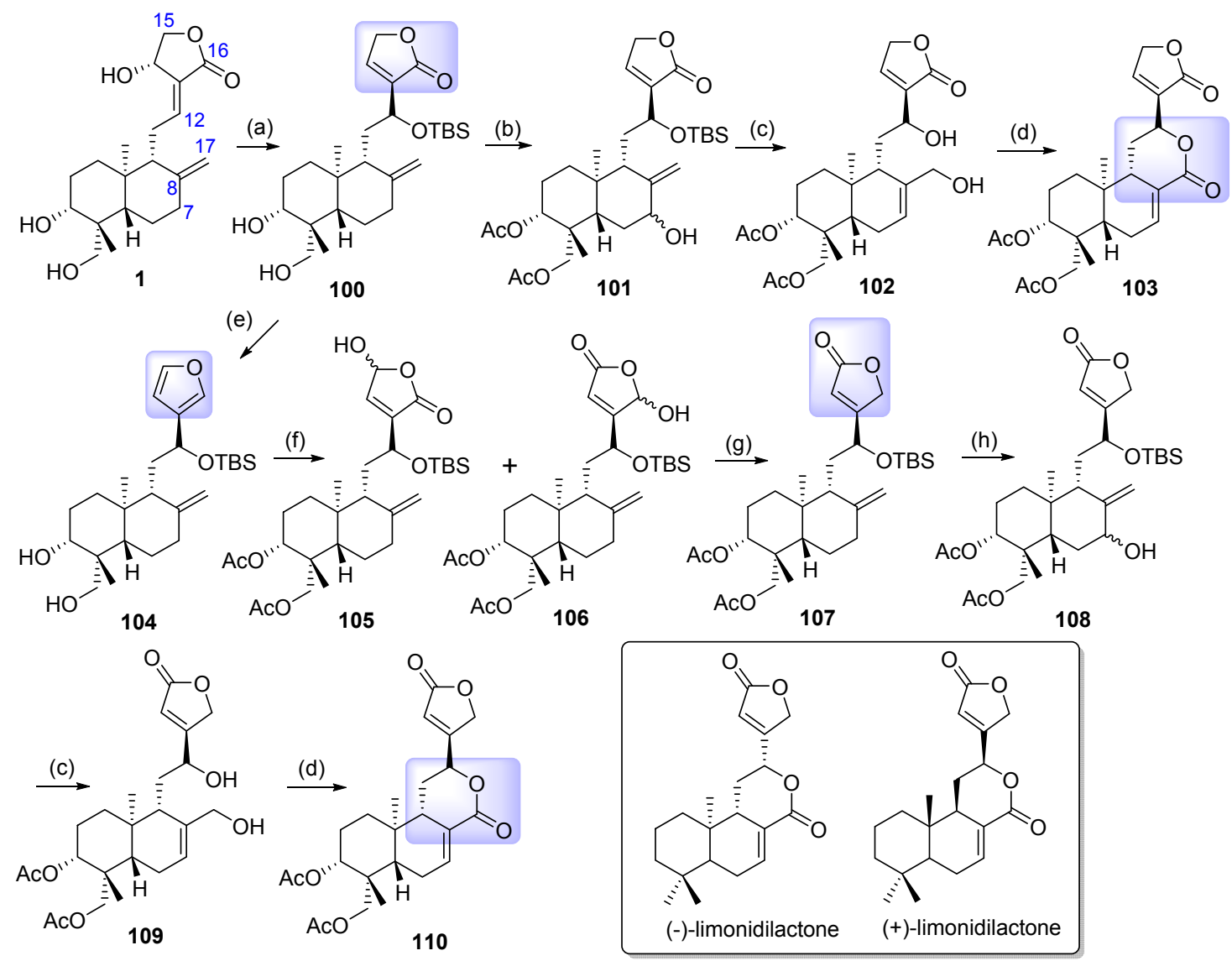

Reagents and conditions: (a) i) 2,2-dimethoxypropane, PPTS, DMSO, $\mathrm{C}_{6} \mathrm{H}_{6}$, reflux, 2 h, ii) PDC, DCM, r.t., 5 h, iii) TBSCl, imidazole, DMF, r.t., 8 h, iv) $\mathrm{AcOH}, \mathrm{H}_{2} \mathrm{O}$, r.t., 15 min; (b) i) $\mathrm{Ac}_{2} \mathrm{O}$, Py, r.t., 6 h, ii) $\mathrm{SeO}_{2}$, TBHP, DCM, r.t., 48 h, (c) i) MsCl, Py, DCM, r.t., 1 h, ii) $\mathrm{NaOAc}$, acetone, $\mathrm{H}_{2} \mathrm{O}$, reflux, $2 \mathrm{~h}$, iii) $\mathrm{AcOH}, \mathrm{H}_{2} \mathrm{O}$, r.t., $24 \mathrm{~h}$; (d) iodobenzene diacetate, TEMPO, DCM, r.t., $1 \mathrm{~h}$; (e) $20 \%$ DIBAL-H in toluene, $-78{ }^{\circ} \mathrm{C}, 2 \mathrm{~h}$; (f) i) $\mathrm{Ac}_{2} \mathrm{O}$, Py, r.t., 2 h, ii) hv, $\mathrm{O}_{2}$, DIEA, rose bengal; (g) $\mathrm{NaBH}_{4}, \mathrm{THF}, 0{ }^{\circ} \mathrm{C}, 2 \mathrm{~h}$; (h) $\mathrm{SeO}_{2}$, TBHP, DCM, r.t., $48 \mathrm{~h}$

图式 18 穿心莲内酯衍生物 $100 \sim 110$ 的合成

Scheme 18 Synthesis of andrographolide derivatives $\mathbf{1 0 0} \sim \mathbf{1 1 0}$

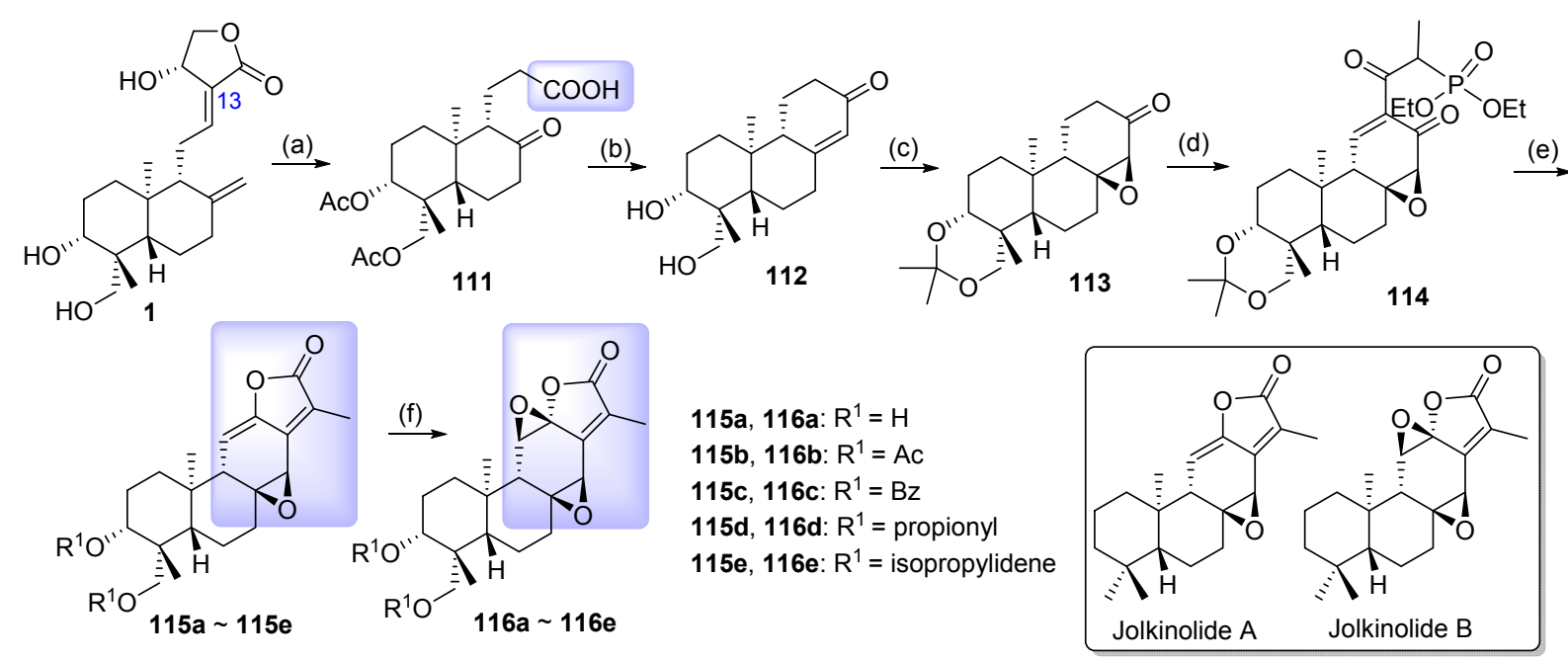

Reagents and conditions: (a) i) $\mathrm{Ac}_{2} \mathrm{O}, \mathrm{ZnCl}_{2}$, reflux, ii) $\mathrm{KBH}_{4}, \mathrm{MeOH}$, r.t., iii) $\mathrm{O}_{3}, \mathrm{DCM},-78{ }^{\circ} \mathrm{C}$; (b) i) $\mathrm{Ac}_{2} \mathrm{O}, \mathrm{NaOAc}$, reflux, ii) $\mathrm{MeLi}$, THF, $30{ }^{\circ} \mathrm{C}$, iii) $10 \% \mathrm{KOH}, \mathrm{MeOH}$, reflux; (c) i) 2,2-dimethoxypropane, PPTS, DCM, reflux, ii) $30 \% \mathrm{H}_{2} \mathrm{O}_{2}, \mathrm{NaOH}, \mathrm{MeOH}$, r.t.; (d) i) $t$ - $\mathrm{BuOCH}(\mathrm{NMe})_{2}$, DMF, $80{ }^{\circ} \mathrm{C}$, ii) $\mathrm{O}_{2}$, TPP, DCM, I-halogen lamp, $-78{ }^{\circ} \mathrm{C}$, iii) 2-(diethoxyphosphoryl)propanoic acid, DCC, DMAP, DCM, r.t.; (e) i) NaH, THF, r.t., ii) $10 \% \mathrm{AcOH}$, THF, reflux; (f) $85 \% \mathrm{~m}$-CPBA, DCM, r.t.

图式 19 穿心莲内酯衍生物 111 116 的合成

Scheme 19 Synthesis of andrographolide derivatives 111 116 
终得到 Jolkinolide 类似物 115a 和 116a, 并以此合成方 法得到 C-3, 19 位羟基酯化衍生物 115b 115e 和 116b 116e. 生物活性方面, 实验以阿霉素为阳性对照, 结果 发现衍生物 116c 在白血病细胞 NB4 上活性相对接近阿 霉素. 尽管该系列衍生物在多项肿瘤细胞株上的表现大 多不尽理想，但其结构设计理念非常值得借鉴.

2014 年, 张大永课题组 ${ }^{[43]}$ 再次公开专利, 由衍生物 104 合成三个以呋喃环为基本骨架的化合物 119a、120a、 $121 \mathbf{a}$, 然后在 C-3, 7, 8, 12, 14, 19 位分别引入不同基团, 得到衍生物 119b $119 \mathrm{~m} 、 120 \mathrm{~b}$ 和 121b 121c (Scheme 20). 研究发现将穿心莲内酯的内酯环改造为呋喃环后, 大部分化合物的抗肿瘤活性均降低, 但化合物 119c 抑 制 NTUB1、MCF-7、MDA-MB-231 和 NP-14 四项肿瘤 细胞株增殖的能力则明显优于穿心莲内酯和阳性对照 顺铂. 所以课题组认为在此骨架上只要引入适当基团便 依然具有改造价值.

\section{6 衍生物与抗肿瘤活性的构效关系总结}

结合上述结构改造工作, 本文初步总结衍生物与抗 肿瘤活性构效关系(图 7)如下: 第一, 将穿心莲内酯 C-14 位羟基酯化或构型翻转醚化、C-3，19 位羟基引入 䒾叉基、C-19 位羟基醚化或氧化成酸后再酰化、C-8, 17 位烯键环氧化以及 $\mathrm{C}-12,13$ 位烯键进行 $[3+2]$ 环加成均
可提高抗肿瘤活性, 而将 C-12,13 位烯键加氢还原则会 失去抗肿瘤作用; 第二, 在 14-去氧穿心莲内酯的 C-12 位引入不同基团对抗肿瘤活性会有不同的影响，其中引 入芳胺基、酯基可增强活性，引入硝甲基或乙酰胺甲基 后再将 C-3,19 位羟基酯化亦可提高抗肿瘤活性，而引入 酰胺基、磺酰胺基或脲基则未发现抗肿瘤能力; 第三, 将脱水穿心莲内酯的 C-15 位亚基取代、C-3,19 位羟基 酯化或者 C-3 位羟基氧化均可增强活性，而 C-3,19 位着 基引入茮叉基或环磷酸酯化、C-8,17 位烯键环氧化或还 原则会造成抗肿瘤活性降低; 第四, 在异穿心莲内酯及 其类似物的 C-15 位引入亚基可增强抗肿瘤活性，在 C-3,19 位羟基引入短链酯基亦可增强活性，但引入长链 酯基或草酰基则会造成活性降低; 第五, 当穿心莲内酯 的内酯环开环或是被完全替换后, 部分衍生物活性有所 增强.

\section{7 启示与展望}

综上所述，有关穿心莲内酯抗肿瘤作用衍生物的合 成已然成为研究热点, 衍生物结构的设计原理具有多样 性, 包括改善药物脂水分配系数、协同前药原理引入 $\mathrm{NO}$ 供体、以其它天然产物结构设计类似物等等. 在生 物活性实验方面部分课题组也并非只停留在肿瘤细胞 活性篮选的层面上, 更有少数工作团队总结出衍生物与

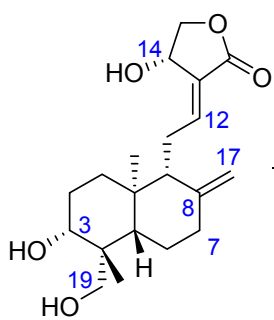

1

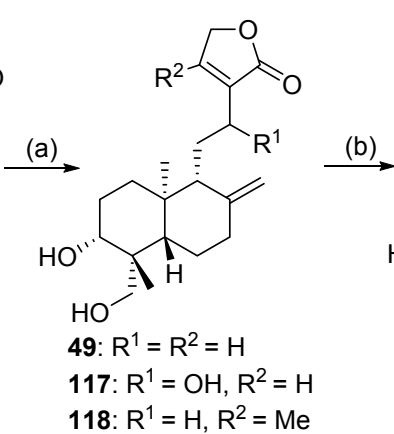

119b: $R^{1}=R^{2}=H, R^{3}=R^{4}=E t C O O, R^{5}=H, R^{6}=C_{2}$ 119c: $R^{1}=R^{2}=H, R^{3}=R^{4}=\mathrm{CHCl}_{2} \mathrm{COO}, \mathrm{R}^{5}=\mathrm{H}, \mathrm{R}^{6}=\mathrm{CH}_{2}$ 119d: $R^{1}=R^{2}=H, R^{3}=R^{4}=P_{2 h O C H} C O O, R^{5}=H, R^{6}=\mathrm{CH}_{2}$ 119e: $R^{1}=R^{2}=H, R^{3}=R^{4}=p-N_{2} \mathrm{C}_{6} \mathrm{H}_{4} \mathrm{COO}, \mathrm{R}^{5}=\mathrm{H}, \mathrm{R}^{6}=\mathrm{CH}_{2}$ 119f: $\mathrm{R}^{1}=\mathrm{R}^{2}=\mathrm{R}^{3}=\mathrm{H}, \mathrm{R}^{4}=p-\mathrm{NO}_{2} \mathrm{C}_{6} \mathrm{H}_{4} \mathrm{COO}, \mathrm{R}^{5}=\mathrm{H}, \mathrm{R}^{6}=\mathrm{CH}_{2}$ 119g: $\mathrm{R}^{1}=\mathrm{R}^{2}=\mathrm{R}^{3}=\mathrm{H}, \mathrm{R}^{4}=p-\mathrm{MeOC}_{6} \mathrm{H}_{4} \mathrm{COO}, \mathrm{R}^{5}=\mathrm{H}, \mathrm{R}^{6}=\mathrm{CH}_{2}$ 119h: $R^{1}=R^{2}=H, R^{3}=R^{4}=O H, R^{5}=H, R^{6}=O$

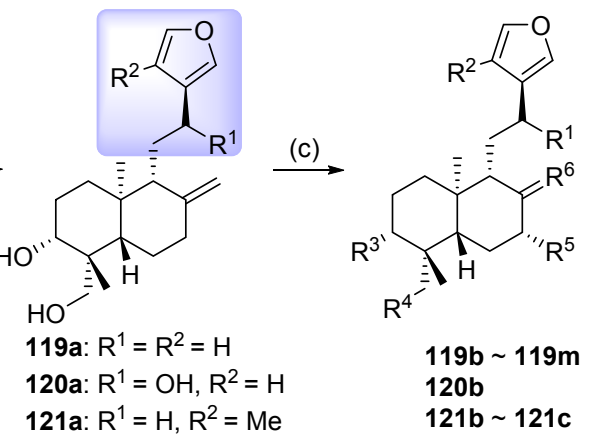

119i: $R^{1}=R^{2}=H, R^{3}=R^{4}=R^{5}=O H, R^{6}=C_{2}$ 119j: $R^{1}=R^{2}=H, R^{3}=R^{4}=A c O, R^{5}=O H, R^{6}=C_{2}$ 119k: $R^{1}=R^{2}=H, R^{3}=R^{4}=$ EtCOO, $R^{5}=O H, R^{6}=C_{2}$ 119I: $R^{1}=R^{2}=H, R^{3}=O, R^{4}=R^{5}=O H, R^{6}=C_{2}$ 119m: $R^{1}=R^{2}=H, R^{3}=N O H, R^{4}=O H, R^{5}=H, R^{6}=C_{2}$ 120b: $R^{1}=$ EtCOO, $R^{2}=H, R^{3}=R^{4}=E t C O O, R^{5}=H, R^{6}=C_{2}$ 121b: $R^{1}=H, R^{2}=M e, R^{3}=R^{4}=R^{5}=O H, R^{6}=C_{2}$ 121c: $R^{1}=H, R^{2}=M e, R^{3}=O, R^{4}=O H, R^{5}=H, R^{6}=C_{2}$

Reagents and conditions: (a) for 49 i) $\mathrm{CH}_{2} \mathrm{~N}_{2}, \mathrm{Et} 2 \mathrm{O}$, r.t., ii) DMF, reflux, iii) $5 \% \mathrm{KHCO}_{3} \mathrm{MeOH}$, reflux; for 117 i) 2,2-dimethoxypropane, $p$-TsOH (cat.), $\mathrm{C}_{6} \mathrm{H}_{6}$, DMSO, $80{ }^{\circ} \mathrm{C}$, ii) $\mathrm{PDC}$, DCM, r.t., iii) $\mathrm{AcOH}, \mathrm{H}_{2} \mathrm{O}$; for 118 i) $\mathrm{Ac}_{2} \mathrm{O}, \mathrm{DCM}, \mathrm{ZnCl}_{2}$, reflux, ii) $\mathrm{KBH}_{4}, \mathrm{MeOH}$, r.t., iii) $5 \% \mathrm{KHCO}_{3} \mathrm{MeOH}$, reflux; (b) DIBAL-H, THF, $-80{ }^{\circ} \mathrm{C}$; (c) for $119 \mathrm{~b} \sim 119 \mathrm{~g}$ and $120 \mathrm{~b}$ anhydrides or $\mathrm{R}^{4} \mathrm{H}$, DMAP, EDCl, DCM, r.t.; for $119 \mathrm{~h}$ i) Ac ${ }_{2} \mathrm{O}$, DMAP, DCM, r.t., ii) $\mathrm{KMnO}_{4}, \mathrm{TBAB}, \mathrm{MgSO}_{4} \cdot 7 \mathrm{H}_{2} \mathrm{O}, \mathrm{C}_{6} \mathrm{H}_{6}, \mathrm{H}_{2} \mathrm{O}, 60{ }^{\circ} \mathrm{C}$, iii) $\mathrm{NaOH}, \mathrm{MeOH}$, r.t.; for $119 \mathrm{i}$ and $120 \mathrm{~b}$ i) $\mathrm{Ac}_{2} \mathrm{O}, \mathrm{DMAP}, \mathrm{DCM}$, r.t., ii) $\mathrm{SeO}$, $t$ - $\mathrm{BuOOH}$, $\mathrm{DCM}$, r.t., iii) $\mathrm{NaOH}, \mathrm{MeOH}$, r.t.; for 119j i) $\mathrm{Ac}_{2} \mathrm{O}$, DMAP, DCM, r.t., ii) $\mathrm{SeO}_{2}$, $t-\mathrm{BuOOH}$, DCM, r.t.; for 119k i) (EtCO) ${ }_{2} \mathrm{O}$, DMAP, DCM, r.t., ii) $\mathrm{SeO}_{2}, t-\mathrm{BuOOH}$, DCM, r.t.; for $119 \mathrm{I}$ and $121 \mathrm{c}$ i) TrCI, DIPEA, DCM, r.t., ii) PDC, DMF, $50{ }^{\circ} \mathrm{C}$, iii) $p$-TsOH, $\mathrm{MeOH}$, r.t., iv) $\mathrm{SeO}_{2}, t-\mathrm{BuOOH}, \mathrm{DCM}$, r.t.; for $119 \mathrm{~m}$ i) $\mathrm{TrCl}$, DIPEA, DCM, r.t., ii) PDC, DMF, $50{ }^{\circ} \mathrm{C}$, iii) $p$-TsOH, $\mathrm{MeOH}$, r.t., iv) $\mathrm{SeO}_{2}$, $t-\mathrm{BuOOH}$, DCM, r.t., v) $\mathrm{NH}_{2} \mathrm{OH}-\mathrm{HCl}, \mathrm{Py}, 40{ }^{\circ} \mathrm{C}$

图式 20 穿心莲内酯衍生物 117 121 的合成

Scheme 20 Synthesis of andrographolide derivatives 117 $\sim \mathbf{1 2 1}$ 


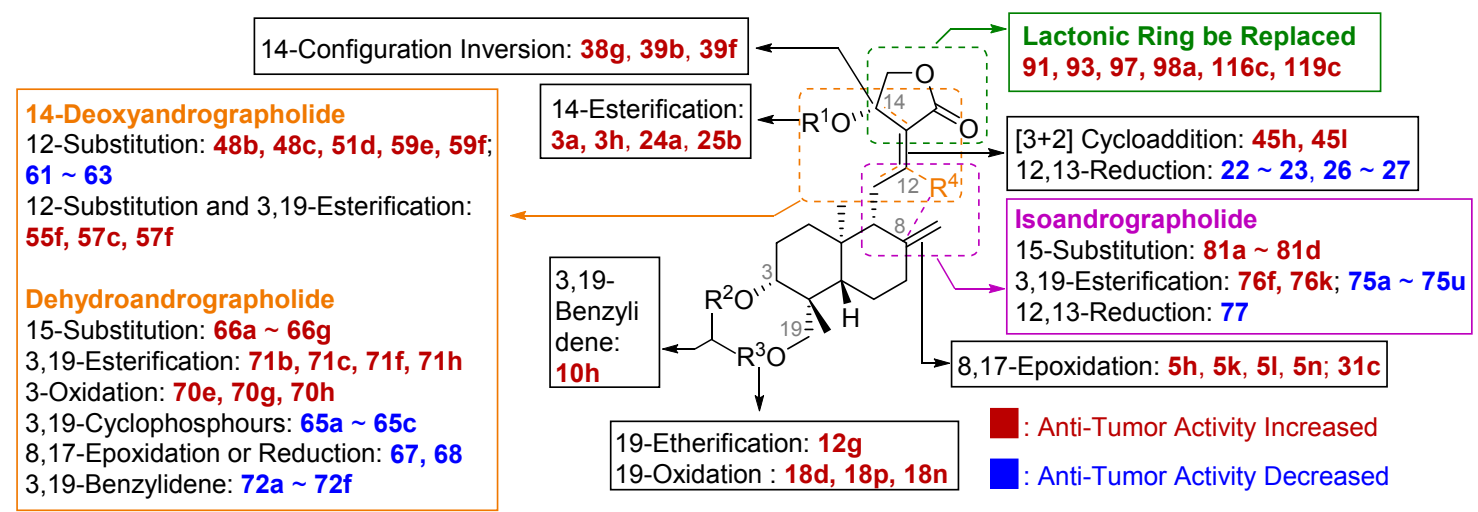

图 7 穿心莲内酯衍生物与抗肿瘤活性的构效关系

Figure 7 SAR of andrographolide derivatives and anti-tumor activity

抗肿瘤作用的构效关系. 然而, 现阶段由于受到专利权 利保护等因素局限, 各课题组的合成工作均在自身所设 计的母核基础上进行修饰和优化, 导致大多研究工作在 得到新型骨架结构后只着重于羟基上引入不同基团，而 忽略了其它官能团的改造, 并且只有少数研究团队对药 物体内实验的活性或毒性等方面进行深入考察.

本文总结穿心莲内酯衍生物与抗肿瘤作用的构效 关系, 其目的是希望在此基础上可篮选出活性更高毒性 更低的衍生物结构. 未来的衍生物改造工作应该集中在 以下几点: 第一, 进一步优化活性较高的已知结构, 如 何降低药物毒性是更需要考虑的重要因素; 第二, 对本 文所述的五类基础骨架结构进行多元化改造, 并尽可能 以简便的操作方法和温和的实验条件合成之; 第三, 寻 找新的改造位点, 设计并合成新的衍生物基本骨架, 异 穿心莲内酯便是很好的成功范例; 第四, 尝试更多更合 理的药物设计思路, 如引入具有抗肿瘤活性的药效团, 深入考察偶联后活性的变化; 第五, 运用计算机辅助药 物设计技术, 在分子水平上阐述其药物作用机制, 为后 续工作提供前瞻性研究. 总之, 国内外许多科学团队仍 在致力于设计合成一类更为理想的具有抗肿瘤活性的 穿心莲内酯衍生物，而加强工作团队之间的合作与交流 同样是成功的关键因素, 希望有更多的课题组能够加入 穿心莲内酯抗肿瘤作用衍生物的合成工作中.

\section{References}

[1] (a) Gorter, M. K. Recl. Trav. Chim. Pays-Bas Belg. 1912, 30, 151. (b) Cava, M. P.; Chan, W. R.; Haynes, L. J.; Johnson, L. F.; Weinstein, B. Tetrahedron 1962, 18, 397.

(c) Fujita, T.; Fujitani, R.; Takeda, Y.; Takaishi, Y.; Yamada, T.; Kido, M.; Miura, I. Chem. Pharm. Bull. 1984, 32, 2117.

[2] Liu, G. L.; Liu, Y. Q. Her. Med. 2006, 25, 48 (in Chinese). (刘国利，刘永琼，医药导报, 2006, 25, 48.)

[3] (a) Zhou, J.; Zhang, S. Y.; Ong, C. N.; Shen, H. M. Biochem. Pharmacol. 2006, 72, 132

(b) Bao, G. Q.; Shen, B. Y.; Pan, C. P.; Zhang, Y. J.; Shi, M. M.;
Peng, C. H. Toxicol. Lett. 2013, 222, 23.

[4] (a) Cheung, H. Y.; Cheung, S. H.; Li, J.; Cheung, C. S.; Lai, W. P.; Fong, W. F.; Leung, F. M. Planta Med. 2005, 71, 1106.

(b) Wong, H. C.; Sagineedu, S. R.; Lajis, N. H.; Loke, S. C.; Stanslas, J. Afr. J. Pharm. Pharmcol. 2011, 5, 225.

[5] (a) Sheeja, K.; Guruvayoorappan, C.; Kuttan, G. Int. Immunopharmacol. 2006, 7, 211.

(b) Shen, K.; Ji, L.; Lu, B.; Xu, C.; Gong, C.; Morahan, G.; Wang, Z. Chem.-Biol. Interact. 2014, 218, 99.

[6] Chen, L. L.; Wang, Z. H. Pharm. Today 2010, 20, 41 (in Chinese). (陈伶俐, 王振华, 今日药学, 2010, 20, 41.)

[7] Yu, B. T.; Zhang, Z. R.; Liu, W. S.; Yang, T.; Wang, P. Chin. Tradit. Pat. Med. 2002, 24, 331 (in Chinese).

(于波涛, 张志荣, 刘文胜, 杨婷, 王平, 中成药, 2002, 24, 331.)

[8] Thunuguntla, S. S. R.; Nyavanandi, V. K.; Nanduri, S. Tetrahedron Lett. 2004, 45, 9357.

[9] Nanduri, S.; Nyavanandi, V. K.; Thunuguntla, S. S. R.; Kasu, S.; Pallerla, M. K.; Ram, P. S.; Rajagopal, S.; Kumar, R. A.; Ramanujam, R.; Babu, J. M.; Vyas, K.; Devi, A. S.; Reddy, G. O.; Akella, V. Bioorg. Med. Chem. Lett. 2004, 14, 4711.

[10] Nanduri, S.; Pothukuchi, S.; Rajagopal, S.; Akella, V.; Pillai, S. B. K.; Chakrabarti, R. WO 2001085710, 2001 [Chem. Abstr. 2001, 135, 371878].

[11] Nanduri, S.; Rajagopal, S.; Pothukuchi, S.; Pillaj, S. B. K.; Chakrabarti, R. WO 2001057026, 2001 [Chem. Abstr. 2001, 135, 152663].

[12] Jada, S. R.; Subur, G. S.; Matthews, C.; Hamzah, A. S.; Lajis, N. H.; Saad, M. S.; Stevens, M. F. G.; Stanslas, J. Phytochemistry 2007, $68,904$.

[13] Jada, S. R.; Hamzah, A. S.; Lajis, N. H.; Saad, M. S.; Stevens, M. F. G.; Stanslas, J. J. Enzyme Inhib. Med. Chem. 2006, 21, 145.

[14] Hocker, H. J.; Cho, K. J.; Chen, C. Y. K.; Rambahal, N.; Sagineedu, S. R.; Shaari, K.; Stanslas, J.; Hancock, J. K.; Gorfe, A. A. Proc. Natl. Acad. Sci. U. S. A. 2013, 110, 10201.

[15] Menon, V.; Bhat, S. Nat. Prod. Commun. 2010, 5, 717.

[16] Sirion, U.; Kasemsook, S.; Suksen, K.; Piyachaturawat, P.; Suksamrarn, A.; Saeeng, R. Bioorg. Med. Chem. Lett. 2012, 22, 49.

[17] (a) Chen, D. S.; Song, Y. P.; Lu, Y. L.; Xue, X. W. Bioorg. Med. Chem. Lett. 2013, 23, 3166.

(b) Xue, X. W.; Li, L.; Song, Y. P.; Lu, Y. L.; Li, J. B. CN 103588738, 2014 [Chem. Abstr. 2014, 160, 356446].

[18] Das, B.; Chowdhury, C.; Kumar, D.; Sen, R.; Roy, R.; Das, P.; Chatterjee, M. Bioorg. Med. Chem. Lett. 2010, 20, 6947.

[19] Preet, R.; Chakraborty, B.; Siddharth, S.; Mohapatra, P.; Das, D.; Satapathy, S. R.; Das, S.; Maiti, N. C.; Maulik, P. R.; Kundu, C. N.; 
Chowdhury, C. Eur. J. Med. Chem. 2014, 85, 95.

[20] (a) Bao, Q.; Zheng, Y. X.; Chen, L. J. Pract. Oncol. 2008, 23, 590 (in Chinese).

(包祺，郑毅雄，陈力，实用肿瘤杂志，2008，23, 590.)

(b) Xie, Y.; Zhou, X. Y.; Hao, H. P.; Wang, G. P. Acta Physiol. Sin. 2014, 66, 252 (in Chinese).

(谢杨, 周雪妍, 郝海平, 王广基, 生理学报, 2014, 66, 252.)

[21] Liu, Z. Y.; Law, W. K.; Wang, D. C.; Nie, X.; Sheng, D. K.; Song, G. R.; Guo, K.; Wei, P.; Ouyang, P. K.; Wong, C. W.; Zhou, G. C. RSC Adv. 2014, 4, 13533.

[22] (a) Hazra, A.; Paira, P.; Sahu, K. B.; Naskar, S.; Saha, P.; Paira, R.; Mondal, S.; Maity, A.; Luger, P.; Weber, M.; Mondal, N. B.; Banerjee, S. Tetrahedron Lett. 2010, 51, 1585.

(b) Dey, S. K.; Bose, D.; Hazra, A.; Naskar, S.; Nandy, A.; Munda, R. N.; Das, S.; Chatterjee, N.; Mondal, N. B.; Banerjee, S.; Saha, K. D. PLoS One 2013, 8, e58055.

(c) Hazra, A.; Bharitkar, Y. P.; Chakraborty, D.; Mondal, S. K.; Singal, N.; Mondal, S.; Maity, A.; Paira, R.; Banerjee, S.; Mondal, N. B. ACS Comb. Sci. 2013, 15, 41.

[23] Nanduri, S.; Rajagopal, S.; Akella, V. WO 2001085709, 2001 [Chem. Abstr. 2001, 135, 358071].

[24] Fan, Q. Q.; Wang, Q. J.; Zeng, B. B.; Wu, Y. L.; Ji, H. J. China Pharm. Univ. 2010, 41, 326 (in Chinese).

(范倩倩, 王秋娟, 曾步兵, 吴玉林, 季晖, 中国药科大学学报, 2010, 41, 326.)

[25] Xu, H.; Huang, W. L.; Zhang, H. B.; Zhou, J. P. Chin. J. Org. Chem. 2005, 25, 1386 (in Chinese).

(徐浩, 黄文龙, 张惠斌, 周金培, 有机化学, 2005, 25, 1386.)

[26] (a) Xu, H.; Wang, X. Y.; Huang, W. L.; Zhang, H. B.; Guo, Q. L.; Liu, W. J. China Pharm. Univ. 2005, 36, 496 (in Chinese).

(徐浩, 王新扬, 黄文龙, 张惠斌, 郭青龙, 刘娓, 中国药科大学 学报, 2005, 36, 496.)

(b) Xu, H.; Huang, W. L.; Zhang, H. B.; Guo, Q. L.; Liu, W. Chin. J. Med. Chem. 2005, 15, 212 (in Chinese).

(徐浩, 黄文龙, 张惠斌, 郭青龙, 刘娓, 中国药物化学杂志, 2005, 15, 212.)

[27] (a) Zhao, W.; Xu, J. J. Chin. J. Convalescent Med. 2012, 21, 607 (in Chinese).

(赵玮, 徐景杰, 中国疗养医学, 2012, 21, 607.)

(b) Zheng, L.; Pei, L.; Xia, J. Z. J. Huaihai Med. 2011, 29, 86 (in Chinese).

(郑亮, 裴雷, 夏加增, 淮海医药, 2011, 29, 86.)
[28] Li, J.; Huang, W. L.; Zhang, H. B.; Wang, X. Y.; Zhou, H. P. Bioorg. Med. Chem. Lett. 2007, 17, 6891.

[29] (a) Xu, C.; Wang, Z. T. Chin. J. Nat. Med. 2011, 9, 46.

(b) Xu, C.; Wang, Z. T. J. China Pharm. Univ. 2011, 42, 29 (in Chinese).

(徐冲, 王峥涛, 中国药科大学学报, 2011, 42, 29.)

[30] (a) Liu, H. M.; Xu, H. W.; Wang, H. F. J. Zhengzhou Univ. 2004, 36, 67 (in Chinese).

(刘宏民，徐海伟，王会芳，郑州大学学报(理学版), 2004, 36, 67.) (b) Xu, H. W.; Zhang, J. Y.; Liu, H. M.; Wang, J. F. Synth. Commun. 2006, 36, 407.

[31] Dai, G. F.; Xu, H. W.; Liu, H. M.; Dong, R. J.; Yan, L. J.; Zhu, L. P.; Li, W. Y.; Jiang, Z. W.; Wang, Y. N.; Wu, F. J. CN 101972247, 2011 [Chem. Abstr. 2011, 154, 318758].

[32] Xu, H. W.; Jiang, P. J.; Li, W. Y.; Wang, J. F.; Liu, H. M. Chin. J. Chem. 2011, 29, 2114

[33] Wang, J. G. Exp. Lab. Med. 2011, 29, 459 (in Chinese). (王继贵, 实验与检验医学, 2011, 29, 459.)

[34] Li, J.; Huang, W. L.; Zhang, H. B.; Zhou, H. P. Lett. Drug Des. Discovery 2010, 7, 176.

[35] Wei, S. F.; Tang, Y. B.; Hua, H. M.; Ohkoshi, E.; Goto, M.; Wang, L. T.; Lee, K. H.; Xiao, Z. Y. Bioorg. Med. Chem. Lett. 2013, 23, 4056.

[36] Wang, X. Y.; Xu, H.; Wu, X. M.; Huang, W. L.; Zhou, J. P. J. China Pharm. Univ. 2005, 36, 504.

[37] Li, J.; Huang, W. L.; Zhang, H. B.; Zhou, H. P. J. China Pharm. Univ. 2007, 38, 299.

[38] Liu, H. M.; Xu, H. W.; Liu, G. Z.; Dai, G. F.; Wang, J. F. $C N$ 100999520, 2007 [Chem. Abstr. 2007, 147, 257908].

[39] Nanduri, S.; Nyavanandi, V. K.; Thunuguntla, S. S. R.; Velisoju, M.; Kasu, S.; Rajagopal, S.; Kumar, R. A.; Rajagopalan, R.; Iqbal, J. Tetrahedron Lett. 2004, 45, 4883.

[40] Marcos, I. S.; Moro, R. F.; Carballares, M. S.; Urones, J. G. Tetrahedron Lett. 1999, 40, 2615.

[41] Zhang, D. Y.; Zhou, B.; Wu, J. Q.; Shi, L. Y.; Wang, K.; Wu, X. M.; Hua, W. Y. CN 102653543, 2012 [Chem. Abstr. 2012, 157, 465734].

[42] Liu, G. F.; Fu, Y. Q.; Yang, Z. Q.; Zhao, H. Q.; Fan, X. M. China J. Chin. Mater. Med. 1988, 13, 291 (in Chinese). (刘桂芳，付玉琴，杨志强，赵慧庆，范雪梅，中国中药杂志, 1988, 13, 291.)

[43] Zhang, D. Y.; Hai, Y.; Wu, X. M. CN 103804330, 2014 [Chem. Abstr. 2014, 161, 39854]. 